Article

\title{
Combining Hydrogeochemical Characterization and a Hyperspectral Reflectance Tool for Assessing Quality and Suitability of Two Groundwater Resources for Irrigation in Egypt
}

\author{
Mohamed Gad ${ }^{1}$ (D), Salah El-Hendawy ${ }^{2,3, *(\mathbb{D})}$, Nasser Al-Suhaibani ${ }^{2}$, Muhammad Usman Tahir ${ }^{2}$, \\ Muhammad Mubushar ${ }^{2}$ and Salah Elsayed ${ }^{4}$ \\ 1 Hydrogeology, Evaluation of Natural Resources Department, Environmental Studies and Research \\ Institute (ESRI), University of Sadat City, Minufiya 32897, Egypt; mohamed.gad@esri.usc.edu.eg \\ 2 Department of Plant Production, College of Food and Agriculture Sciences, King Saud University, KSA, \\ P.O. Box 2460, Riyadh 11451, Saudi Arabia; nsuhaib@KSU.EDU.SA (N.A.-S.); mtahir@ksu.edu.sa (M.U.T.); \\ mubusharuaf@gmail.com (M.M.) \\ 3 Department of Agronomy, Faculty of Agriculture, Suez Canal University, Ismailia 41522, Egypt \\ 4 Agricultural Engineering, Evaluation of Natural Resources Department, Environmental Studies \\ and Research Institute, University of Sadat City, Minufiya 32897, Egypt; salah.emam@esri.usc.edu.eg \\ * Correspondence: mosalah@ksu.edu.sa; Tel.: +966-5353-18364
}

Received: 16 June 2020; Accepted: 28 July 2020; Published: 31 July 2020

\begin{abstract}
Hyperspectral reflectance sensing provides a rapid and cost-effective technique for assessing the suitability of groundwater for irrigation by monitoring real-time changes in its quality at a large scale. In this study, we assessed the quality of 15 groundwater samples from El Fayoum depression in the Western Desert (WD) and 25 groundwater samples from the Central Nile Delta (CND) in Egypt using a traditional approach of the physiochemical parameters, irrigation water quality indicators (IWQIs), and hydrochemical facies. The spectral reflectance data of the water surface was used to build new simple reflectance indices (SRIs), and the performance of these indices for assessing IWQIs was compared with those by partial least square regression (PLSR) that was based on all SRIs or the full-spectrum ranges. Generally, the groundwater of the CND was fresher and more suitable for irrigation purposes than those of the WD. Based on the six IWQIs, $\sim 6.7-60.0 \%$ and $85.0-100.0 \%$ of the groundwater samples of the WD and CND, respectively, were categorized as highly suitable for irrigation purposes. Based on hydrochemical facies, $\mathrm{Na}-\mathrm{Cl}$ and $\mathrm{Ca}-\mathrm{HCO}_{3}$ were dominant in the WD and CND, respectively, as well as the alkali earth metals $\left(\mathrm{Na}^{+}+\mathrm{K}^{+}\right)$, which significantly exceeded the alkaline earth metals $\left(\mathrm{Ca}^{2+}+\mathrm{Mg}^{2+}\right)$ in the WD, with the reverse for the CND. Most developed SRIs had a moderate, weak, and moderate to strong relationship with physiochemical parameters and IWQIs in the WD, CND, and across both regions, respectively. The PLSR models based on all SRIs provided a more accurate estimation of IWQIs in calibration and validation datasets than those based on full-spectrum ranges, and both PLSR models provided better estimation than the individual SRIs. These findings support the feasibility of using ground reflectance measurements as a fast and low-cost tool for the assessment and management of groundwater for irrigation in arid and semiarid regions.
\end{abstract}

Keywords: irrigation water quality indicators; partial least squares regression; physicochemical parameters; Piper diagram; potential salinity; proximal remote sensing; sodium absorption ratio

\section{Introduction}

Water shortages, especially for agriculture, are prevalent in countries in arid and semiarid regions and they have become more and more severe in these regions in recent years due to a lack of water 
resources and abrupt climatic changes [1]. In the world's arid regions, the agriculture sector depends on groundwater as a primary water source for irrigation. Generally, groundwater is used to irrigate $30-40 \%$ of irrigated land [2]. However, in recent decades, various human activities have resulted in groundwater pollution drastically and caused a periodic change in their quality. Therefore, regular assessment of groundwater quality is necessary to identify its suitability for irrigation purposes where the productivity and quality of crops depend highly on soil characteristics and quality of irrigation water.

Several important water quality indicators are frequently applied to assess the quality and suitability of groundwater for irrigation. Generally, the water quality index (WQI), which was initially proposed by Brown et al. [3] and is based on the primary parameters of water quality, namely major cations and ions, heavy metals, temperature, and $\mathrm{pH}$, is frequently used to classify the quality of water for drinking purposes. While, the irrigation water quality indicators (IWQIs), namely percentage sodium (\%Na), sodium absorption ratio (SAR), soluble sodium percentage (SSP), total dissolved solids (TDS), potential salinity (PS), total hardness, and Kelly's index (KI), which are based on the major cations $\left(\mathrm{K}^{+}, \mathrm{Ca}^{2+}\right.$, and $\left.\mathrm{Mg}^{2+}\right)$ and ions $\left(\mathrm{Na}^{+}, \mathrm{Cl}^{-}\right.$, and $\left.\mathrm{SO}_{4}{ }^{2-}\right)$, are frequently used to assess the suitability of water for irrigation purposes [4-8]. When the values of WQI and IWQIs are outside of standard requirements, there are direct and indirect negative effects on soil characteristics and plant growth, which ultimately results in significant reductions in crop production without contributing to solve the water shortage problems in the agriculture sector. Therefore, accurate and efficient assessment of these indicators can improve the management and effective use of groundwater.

The standard approach for assessing different water quality indicators, which includes collecting samples from the field at fixed points and then analyzing the samples in the laboratory and comparing the data with a reference standard following protocols, is practicable and highly accurate. However, the methods used for assessing water quality should not only accurately reflect spatial variations in water quality, but they should also conveniently monitor water quality levels in an inexpensive and fast manner to provide a real-time estimation of spatial and temporal variations in water quality on a large scale, which is very important for the comprehensive assessment and management of groundwater quality. For instance, although the WQI can be assessed using a simple mathematical instrument, which transforms the large quantity of water characterization data into a single value that represents the water quality level and reflects overall water quality levels [6,9-11], the WQI does not indicate spatial and temporal variations in water quality [12]. In addition, although different geometrical diagrams and mathematical models are frequently applied in groundwater chemistry assessment, they are generally costly and time-inefficient, tedious, and require significant input and model assumptions, which limit estimations to only being reliable at regional or smaller scales $[13,14]$. Due to the limitations of standard methods for monitoring and managing groundwater quality in real-time and on a large scale, there is an urgent need to apply reliable, practical, rapid, and economical monitoring tools, which can be deployed easily and help decision-makers to assess key indicators relevant to groundwater quality in a comprehensive manner.

With the rapid developments in space information and increasing use of computer applications, different airborne, satellite, or proximal remote sensing techniques have been demonstrated to be cost-effective and applicable on a large scale for integrative assessment of several IWQIs [12,15-19]. The concept behind these techniques is that the different sensors of these tools can detect changes in the optical properties of the water surface at various wavelengths. The optical properties of the water surface are significantly interlinked with the changes that take place in the physical, chemical, biological, and hydrological characteristics of the water. Therefore, the spectral signatures reflected from the water surface can be exploited directly or indirectly to assess different water quality indicators, such as temperature, $\mathrm{pH}$, salinity, total suspended solids (TSS), chemical and biological oxygen demand, total phosphorus, ammonia nitrogen $\left(\mathrm{NH}_{3}-\mathrm{N}\right)$, and dissolved organic carbon [18-27].

Space-borne optical remote sensing systems, such as satellites and airborne remote sensing systems, have a wide spatial coverage and are commonly used to detect different water quality indicators. 
However, the spectral resolution of these systems is insufficient and results in uncertainty in extracted water quality data. This is because $\sim 90-98 \%$ of the signals obtained by these systems are from the surface of the water and atmosphere, and only $2-10 \%$ of the signal is from the water components. This results in complexity in the data of the optical properties of the water surface, which makes the assessment of water quality using these systems inaccurate [19]. A ground-based hyperspectral system can be a useful tool to overcome the limitation of external interference in water quality assessment. This system can obtain high-resolution spectral information and ensure the accuracy of spectral inversion because of the proximity between the optical sensors and the target. In addition, the data of this system has the advantages of a large amount of information, a large number of bands, and strong quantitative inversion flexibility [27]. Generally, in passive mode, this system uses sunlight, and in active mode, it uses its own light to detect the spectral signatures reflected from the water surface in the visible (VIS), near-infrared (NIR), and shortwave-infrared (SWIR) parts of the spectrum [20,28]. Therefore, this system could be used to more effectively and efficiently monitor spatial and temporal variations that take place in surface groundwater quality based on the substantial changes that take place in the reflectance signature from the water surface in the three parts of the spectrum.

Several studies have found a close relationship between different water quality characteristics and spectral reflectance from the water surface at specific wavebands, especially in the VIS and NIR bands. For example, Gitelson et al. [15] concluded that the spectral reflectance in the 700-900 nm range is the optimal spectrum range for estimating the concentration of TSS using remote sensing. Vinciková et al. [22] also reported that the spectral reflectance ratio in the red edge $(714 \mathrm{~nm})$ and red $(650 \mathrm{~nm})$ regions provide the best estimate for chlorophyll concentrations, while simple spectral reflectance in NIR wavebands, especially at $806 \mathrm{~nm}$, is well correlated with the TSS of water $\left(\mathrm{r}^{2}=0.89\right)$. A close relationship between colored dissolved organic matter and spectral reflectance in the blue and green regions of the spectrum was also reported by Miller et al. [29]. In addition, spectral reflectance in the blue $(450-510 \mathrm{~nm})$ and green $(500-600 \mathrm{~nm})$ wavebands are sensitive to changes in concentrations of total phosphorus in water [18,30-32]. Whereas the majority of researchers have used a space-borne optical remote sensing system to assess water quality indicators, there has been limited investigation of the potential of using a high-resolution spectroradiometer technique for assessing these parameters in situ, especially for groundwater. In situ hyperspectral measurements are useful for monitoring water quality in a reliable manner and could be used to estimate water quality parameters in the water column by estimating the water quality of samples collected from above and below the water surface. This is a very important step for comprehensive assessment and management of groundwater, which is the primary source of irrigation water in arid regions. Such in situ hyperspectral measurements could also be used to calibrate and validate the data acquired by space-borne optical remote sensing systems.

As groundwater quality is affected by several factors, the analysis of hyperspectral reflectance data using an appropriate statistical method is a critical step in unraveling the relationship between these data and specific water quality parameters. Generally, most previous studies have focused on investigating relationships between measured water quality indicators and specific spectral reflectance indices (SRIs). However, these SRIs focus on only 2-3 specific wavelengths. Therefore, instead of formulating individual specific SRIs, a wide range of wavelengths within the full VIS-SWIR spectrum could be applied on an empirical basis to fit the best model for estimating the traits of interest. Several multivariate analyses, such as partial least square regression (PLSR) models, are typically used to create a reliable linear relationship between a set of independent variables, such as full-spectrum ranges and SRIs, and response variables, which are often measured parameters. These analyses consider a set of SRIs as a single independent index and create a more flexible model for indirect estimation of measured parameters when the number of SRIs exceeds the number of measured parameters substantially $[12,27,33,34]$. Generally, hyperspectral data allow various multivariate analyses to consider the full VIS-SWIR spectrum and various SRIs. Thus far, few reports evaluate the performance of PLSR models for indirectly estimating IWQIs of groundwater. There is only one study that focuses on predicting the WQI using a model of support vector regression based on 
SRIs [12]. Therefore, we propose that developing reliable models using PLSR based on different SRIs and full-spectrum ranges will help in the precise assessment and management of groundwater quality for arid and semiarid regions.

The primary objectives of this study were to (1) evaluate the quality of groundwater for irrigation purposes using different physiochemical parameters, IWQIs, and hydrochemical facies in two distinct regions of Egypt, (2) identify the most sensitive wavelengths in the VIS-NIR spectrum that correspond to the measured IWQIs using different contour maps, (3) utilize these effective wavelengths for building specific SRIs, (4) examine the potential of these new SRIs and published SRIs for indirectly estimating IWQIs, and (5) compare the performance of SRIs and different PLSR models, which are based on SRIs or full-spectrum ranges (302-1148 nm), for estimating IWQIs.

\section{Materials and Methods}

\subsection{Study Area}

This study was conducted in two different regions, which represents the Quaternary aquifer, the El Fayoum depression in the Western Desert (WD), and the Central Nile Delta (CND), Egypt (Figure 1). The WD lies between $29^{\circ} 0^{\prime}-29^{\circ} 30^{\prime} \mathrm{N}$ and $30^{\circ} 20^{\prime}-31^{\circ} 10^{\prime} \mathrm{E}$, with an area of $\sim 1200 \mathrm{~km}^{2}$, while the CND lies between $30^{\circ} 30^{\prime}-30^{\circ} 55^{\prime} \mathrm{N}$ and $30^{\circ} 40^{\prime}-31^{\circ} 00^{\prime} \mathrm{E}$, with an area of $\sim 600 \mathrm{~km}^{2}$ (Figure 1).

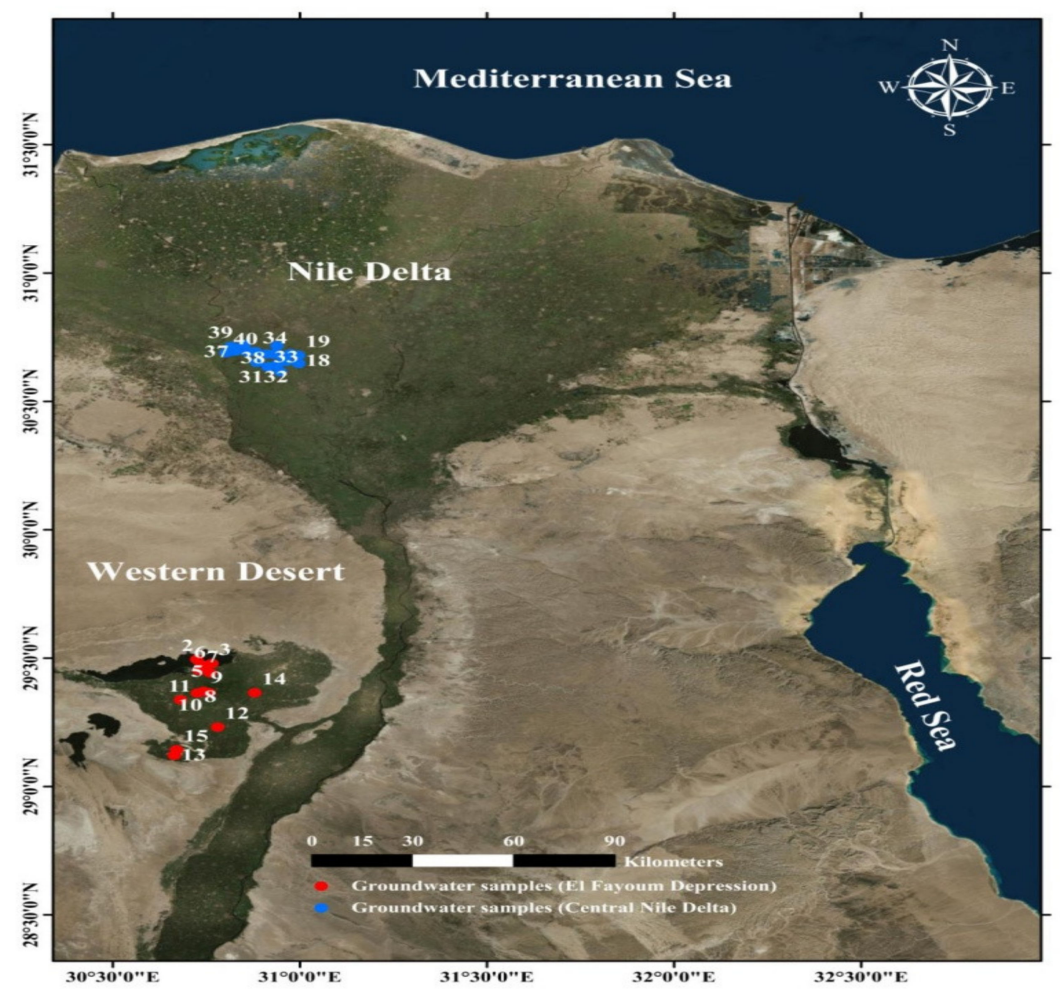

Figure 1. Location of the El Fayoum depression in the Western Desert (red points) and the Central Nile Delta (green points) and their measuring points.

\subsection{Sample Collection and Analytical Procedures}

During the summer of 2019, 40 groundwater samples were collected from depths of 5-100 $\mathrm{m}$ from the Quaternary aquifer to assess groundwater quality for irrigation purposes: 15 samples were collected from the WD and 25 samples were collected from the CND (Figure 1). The study areas and collected samples were identified using a handheld Magellan GPS 315 and the UTM coordinate system (Figure 1). The collected groundwater samples were maintained at $4{ }^{\circ} \mathrm{C}$ to minimize 
changes in water physicochemical characteristics until they were delivered to the laboratory for physiochemical analysis.

Twelve different physiochemical parameters, including temperature $\left(\mathrm{T}^{\circ} \mathrm{C}\right)$, hydrogen ion activity $(\mathrm{pH})$, total dissolved solids (TDS), major cations $\left(\mathrm{K}^{+}, \mathrm{Na}^{+}, \mathrm{Mg}^{2+}, \mathrm{Ca}^{2+}\right)$, and major anions $\left(\mathrm{Cl}^{-}\right.$, $\mathrm{NO}_{3}{ }^{-}, \mathrm{HCO}_{3}{ }^{-}, \mathrm{CO}_{3}{ }^{2-}, \mathrm{SO}_{4}{ }^{2-}$ ), which are indicators of drinking water quality, were determined according to standard analytical methods [35]. Temperature, $\mathrm{pH}$, and TDS were recorded at the time of sampling using a portable calibrated conductivity multi-parameter instrument (Hanna $\mathrm{HI}$ 9033), which was calibrated using standard solutions. The concentrations of $\mathrm{Mg}^{2+}$ and $\mathrm{Ca}^{2+}$ were determined using the ethylenediamine tetra-acetic acid (EDTA) titrimetric method, while $\mathrm{K}^{+}$and $\mathrm{Na}^{+}$ concentrations were analyzed using a flame photometer (ELEX 6361, Eppendorf AG, Hamburg, Germany). The concentration of $\mathrm{Cl}^{-}$was estimated by titration using silver nitrate and $\mathrm{HCO}_{3}{ }^{-}$, and $\mathrm{CO}_{3}{ }^{2-}$ concentrations were determined using the titrimetric method. The contents of $\mathrm{SO}_{4}{ }^{2-}$ and $\mathrm{NO}_{3}{ }^{-}$were determined using an ultraviolet (UV) visible spectrophotometer (DR/2040 Loveland, CO, USA).

The twelve different physiochemical parameters were used to calculate the different IWQIs, such as IWQ, \%Na, SAR, SSP, PS, and KI (Table 1).

Table 1. Full name, abbreviation, formula, and references for different irrigation water quality indicators (IWQIs) applied in this study.

\begin{tabular}{ccc}
\hline IWQIs & Formula & References \\
\hline Irrigation water quality (IWQ) & $\sum_{\mathrm{i}=1}^{\mathrm{n}} \mathrm{Q}_{\mathrm{i}} \mathrm{W}_{\mathrm{i}}$ & {$[3]$} \\
Percentage sodium (\%Na) & $\left.\left(\mathrm{Na}^{+}+\mathrm{K}^{+}\right) /\left(\mathrm{Ca}^{2+}+\mathrm{Mg}^{2+}+\mathrm{Na}^{+}+\mathrm{K}^{+}\right)\right] \times 100$ & {$[36]$} \\
Sodium adsorption ratio (SAR) & {$\left[\mathrm{Na}^{+} / \sqrt{ }\left(\mathrm{Ca}^{2+}+\mathrm{Mg}^{2+}\right) / 2\right] \times 100$} & {$[37]$} \\
Soluble sodium percentage (SSP) & {$\left[\mathrm{Na}^{+} /\left(\mathrm{Na}^{+}+\mathrm{Ca}^{2+}+\mathrm{Mg}^{2+}\right)\right] \times 100$} & {$[36]$} \\
Potential salinity(PS) & $\mathrm{Cl}^{-}+\left(\mathrm{SO}_{4}^{2-} / 2\right)$ & {$[38]$} \\
Kelly's index (KI) & $\mathrm{Na}^{+} /\left(\mathrm{Ca}^{2+}+\mathrm{Mg}^{+2}\right)$ & {$[39]$} \\
\hline
\end{tabular}

The IWQ is a dimensionless computed index that reflects the composite influences of overall water quality. It transforms several selected physiochemical parameters and their concentrations in a water sample into a single value, which is a quantitative and extensive interpretation of overall water quality and its suitability for various purposes $[6,11,40]$. The IWQ was calculated as the sum of the individual values of each selected physiochemical parameter $\left(Q_{i}\right)$ weighted by the importance of this parameter to the evaluation of the overall water quality $\left(\mathrm{W}_{\mathrm{i}}\right)$ using the following equation [3]:

$$
\mathrm{IWQ}=\sum_{\mathrm{i}=1}^{\mathrm{n}} \mathrm{Q}_{\mathrm{i}} \mathrm{W}_{\mathrm{i}}
$$

where $\mathrm{Q}_{\mathrm{i}}$ is the relative quality of the $i$ th physiochemical parameter, $\mathrm{W}_{\mathrm{i}}$ is the relative weight of the $i$ th physiochemical parameter, and $\mathrm{i}$ is the number of selected physiochemical parameters, which is five in this study: $\mathrm{EC}, \mathrm{Na}^{+}, \mathrm{Cl}^{-}, \mathrm{HCO}_{3}{ }^{-}$and SAR.

The values of $Q_{i}$ and $W i$ were determined depending on each individual physiochemical parameter value and finally taking account into the criteria. The $Q_{i}$ values were calculated using the following equation:

$$
Q_{i}=Q_{\text {max }}-\left(\frac{\left[\left(X_{i j}-X_{\text {inf }}\right) \times Q_{\text {imap }}\right]}{X_{\text {amp }}}\right)
$$

where, $Q_{\max }$ is the maximum value of $Q i$ for each class to which the parameter belongs; Xij and Xinf are respectively referring to the observed value of each parameter and the lower limit value of the class to which the parameter belongs; Qimap is the class amplitude; and Xamp corresponds to class amplitude to which the parameter belongs. In order to evaluate the Xamp of the last class of each parameter, the upper limit was considered to be the highest value determined in the analysis of the water samples. 
The values of $W i$ were normalized and their final sum equal to one according to the following equation:

$$
W_{i}=\frac{\sum_{j=1}^{k} F_{j} A_{i j}}{\sum_{j=1}^{k} \sum_{i=1}^{n} F_{j} A_{i j}}
$$

where, $i$ is the number of parameters selected in IWQ and ranging from 1 to $n ; j$ is the number of factors to choose in IWQ and varying from 1 to $\mathrm{k}$; $A i j$ is the explainability of parameter $i$ by factor $j$; and $F$ is a constant value of component 1 .

Percent $\mathrm{Na}^{+}$is an indicator of $\mathrm{Na}^{+}$hazard where the high concentration of it in irrigation water affects the soil texture and permeability. In addition, $\mathrm{Na}^{+}$reacts with $\mathrm{Cl}^{-}$and $\mathrm{CO}_{3}{ }^{2-}$ to form saline soils and alkaline soils, respectively. Therefore, \%Na is one important indicator which helps in categorization of groundwater for irrigation purposes. The SAR is another indicator for irrigation water quality, which can also reduce the soil permeability and thus inhibit the absorption of water by crops. Therefore, the low value of SAR of irrigation water is desirable. The PS, which is defined as the summation of $\mathrm{Cl}^{-}$and half of the $\mathrm{SO}_{4}{ }^{2-}$, is also a very important index for determining the suitability of groundwater for irrigation purposes. The $\mathrm{KI}$ is based on the $\mathrm{Na}^{+}$concentration against $\mathrm{Ca}^{2+}$ and $\mathrm{Mg}^{2+}$. When the $\mathrm{KI}$ is greater than 1 , this indicates an excess of $\mathrm{Na}^{+}$in waters. Therefore, water with $\mathrm{KI} \leq 1$ is desirable for irrigation. The ranges and classification of groundwater based on the different indicators of IWQIs are presented with their references in Table 5.

Piper's tri-linear diagram and Chadha's diagram were also applied to assess the major geochemical processes that control the water quality evolution. In Piper's diagram [41], the proportions of the major cations and anions in milliequivalents (meq $\mathrm{L}^{-1}$ ) are plotted in two separate triangle shapes, and information combined from the two triangles is plotted in a diamond shape, which represents the overall characteristics of groundwater. Chadha's diagram [42], which is square- or rectangle-shaped, is obtained when the difference in milliequivalent percentage between alkaline earth metals $\left(\mathrm{Ca}^{2+}+\mathrm{Mg}^{2+}\right)$ and alkali metals $\left(\mathrm{Na}^{+}+\mathrm{K}^{+}\right)$are plotted on the $\mathrm{X}$ axis against the difference in milliequivalent percentage between weak acidic anions $\left(\mathrm{CO}_{3}{ }^{2-}+\mathrm{HCO}_{3}{ }^{-}\right)$and strong acidic anions $\left(\mathrm{Cl}^{-}+\mathrm{SO}_{4}{ }^{2-}\right)$ on the $\mathrm{Y}$ axis. The Aquachem 3.7 software package and MS Excel spreadsheets were used to create Piper's tri-linear diagram and Chadha's diagram, respectively.

\subsection{Spectral Reflectance Measurements of Groundwater Samples}

The spectral reflectance of groundwater samples was measured using a portable handheld spectrometer (tec5 AG, Oberursel, Germany) containing two different units. One unit was for detecting solar radiation as a reference signal, while the second unit captured the solar radiation reflected from the water surface at $302-1148 \mathrm{~nm}$ with a $2 \mathrm{~nm}$ sampling interval and a field of view of $12^{\circ}$. The groundwater samples were placed in black cylindrical cups with a diameter of $25 \mathrm{~cm}$ and a depth of $10 \mathrm{~cm}$, and the sensor was held vertically at $\sim 25 \mathrm{~cm}$ above the water surface in the nadir orientation with a measuring surface of $0.05 \mathrm{~m}^{2}$. Spectral data were collected under sunny and windless conditions, and before each measurement, a polytetrafluoroethylene (PTFE) white standard, which provides a near $100 \%$ reflectance, was used to calibrate the reflectance measurements. To overcome any significant changes in solar irradiance and atmospheric conditions, measurements between water target and a PTFE white panel were done within a very short time period. The cylindrical cups were placed on a black sheet to prevent spectral reflectance from the background. An average of two sequential measurements and 10 scans for each was considered as the measured spectrum per each groundwater sample [19].

\subsection{Selection of Developed and Published Spectral Reflectance Indices}

The SRIs were developed using data extracted from contour maps, which showed the coefficients of determination $\left(\mathrm{R}^{2}\right)$ matrices of the relationships between each of six IWQIs and all possible two-band combinations in the range of $302-1148 \mathrm{~nm}$. The newly developed SRIs were selected from the contour 
maps based on hotspots of higher $\mathrm{R}^{2}$ values. The lattice package for R 3.0.2 (R Foundation, Vienna, Austria) software was used to establish the different contour maps. The formula for the developed and published SRIs is listed in Table 2.

Table 2. Formula and references of different spectral reflectance indices (SRIs) developed in this study and selected from the literature.

\begin{tabular}{ccc}
\hline SRIs & Formula & Reference \\
\hline Ratio of reflectance between 326 and $1106 \mathrm{~nm}$ & $\mathrm{R}_{326} / \mathrm{R}_{1106}$ & This work \\
Ratio of reflectance between 330 and $456 \mathrm{~nm}$ & $\mathrm{R}_{330} / \mathrm{R}_{456}$ & This work \\
Ratio of reflectance between 332 and $1106 \mathrm{~nm}$ & $\mathrm{R}_{332} / \mathrm{R}_{1106}$ & This work \\
Ratio of reflectance between 334 and $550 \mathrm{~nm}$ & $\mathrm{R}_{334} / \mathrm{R}_{550}$ & This work \\
Ratio of reflectance between 334 and $670 \mathrm{~nm}$ & $\mathrm{R}_{334} / \mathrm{R}_{670}$ & This work \\
Ratio of reflectance between 334 and $1100 \mathrm{~nm}$ & $\mathrm{R}_{334} / \mathrm{R}_{1100}$ & This work \\
Ratio of reflectance between 338 and $670 \mathrm{~nm}$ & $\mathrm{R}_{338} / \mathrm{R}_{670}$ & This work \\
Ratio of reflectance between 596 and $630 \mathrm{~nm}$ & $\mathrm{R}_{596} / \mathrm{R}_{630}$ & This work \\
Ratio of reflectance between 622 and $594 \mathrm{~nm}$ & $\mathrm{R}_{622} / \mathrm{R}_{594}$ & This work \\
Ratio of reflectance between 776 and $770 \mathrm{~nm}$ & $\mathrm{R}_{776} / \mathrm{R}_{770}$ & This work \\
Water index (WI) & $\mathrm{R}_{950} / \mathrm{R}_{970}$ & {$[43]$} \\
Normalized water index-3 (NWI-3) & $\left(\mathrm{R}_{970}-\mathrm{R}_{880}\right) /\left(\mathrm{R}_{970}+\mathrm{R}_{880}\right)$ & {$[44]$} \\
Ratio of reflectance between 359 and $675 \mathrm{~nm}$ & $\mathrm{R}_{359} / \mathrm{R}_{675}$ & {$[12]$} \\
Ratio of reflectance between 359 and $854 \mathrm{~nm}$ & $\mathrm{R}_{359} / \mathrm{R}_{854}$ & {$[12]$} \\
\hline
\end{tabular}

\subsection{Statistical Analysis}

SPSS 22 (SPSS Inc., Chicago, IL, USA) was used to calculate descriptive statistics, including the minimum, maximum, mean, and standard deviation (SD) of the physicochemical parameters, IWQIs, and SRIs. Correlation matrices between physicochemical parameters, IWQIs, and SRIs were determined using Pearson's correlation coefficients (r) for each region and across the two regions, and CoStat 6.311 for Windows (CoHort software, Berkeley, CA, 94701, USA) was used for defined r values and to draw the correlation matrix.

Partial least square regression was performed to relate fourteen SRIs or the full-spectrum ranges $(302-1148 \mathrm{~nm})$ to the target variables, which were the different IWQIs. The PLSR model can effectively analyze data with strong multi-collinearity and noise in the data by maximizing the covariance between the scores of the input and target variables [45]. Calculating the optimal number of latent variables (ONLFs), which is a very important step in PLSR analysis to calibrate data without under- or over-fitting data, was done for each IWQI by leave-one-out cross-validation (LOOCV). The ONLFs was identified when the predicted residual error sum of squares value was at its minimum [46]. The predictive performance of different PLSR models in calibration and validation datasets was based on the maximum value of the coefficient of determination $\left(R^{2}\right)$ and slope, and the minimum value of the root mean squared error (RMSE). The PLSR analysis was performed using Unscrambler X 10.2 (CAMO Software AS, Oslo, Norway) software. The relationship between calculated and predicted values for each IWQI was fitted using Sigma Plot 11.0 for Windows (Systat Software Inc., Point Richmond, Chicago, IL, USA).

\section{Results}

\subsection{Physicochemical Parameters and Irrigation Water Quality Indicators}

In general, the $\mathrm{pH}$ of the groundwater samples for both regions was alkaline, ranging from 6.90 to 8.90 , with a mean of 7.76 (Table 3). The maximum temperature of the WD was $5.6{ }^{\circ} \mathrm{C}$ higher than that of the CND, and the minimum temperature of $27^{\circ} \mathrm{C}$ was similar for both regions (Table 3). In addition, the groundwater samples from the WD exhibited higher concentrations of TDS and major cations and anions than the CND (Table 3). Furthermore, $\mathrm{Na}^{+}$in the WD and $\mathrm{Ca}^{2+}$ in the CND were most dominant of all the major cations (Table 3). The concentrations of $\mathrm{Na}^{+}$and $\mathrm{Ca}^{2+}$ constituted $58.2 \%$ and $48.9 \%$ of the total concentration of cations, respectively (Table 3 ). In addition, 
$\mathrm{Cl}^{-}$and $\mathrm{SO}_{4}{ }^{2-}$ in the $\mathrm{WD}$ and $\mathrm{HCO}_{3}{ }^{-}$in the $\mathrm{CND}$ were most dominant among the major anions (Table 3). The concentrations of $\mathrm{Cl}^{-}, \mathrm{SO}_{4}{ }^{2-}$, and $\mathrm{HCO}_{3}{ }^{-}$constituted $38.2 \%, 40.0 \%$, and $53.4 \%$ of the total concentration of anions, respectively (Table 3).

Table 3. Minimum (Min), maximum (Max), mean, and standard deviation (SD) of the concentrations of different measured physicochemical parameters of groundwater samples in the Western Desert and Central Nile Delta. All values are expressed in $\mathrm{mg} \mathrm{L}^{-1}$ except for temperature $\left({ }^{\circ} \mathrm{C}\right)$ and $\mathrm{pH}$.

\begin{tabular}{|c|c|c|c|c|c|c|c|c|c|c|c|c|}
\hline \multicolumn{13}{|c|}{ El Fayoum Depression, Western Desert (WD, $n=15)$} \\
\hline & Temp. & $\mathrm{pH}$ & TDS & $\mathrm{K}^{+}$ & $\mathrm{Na}^{+}$ & $\mathrm{Mg}^{2+}$ & $\mathrm{Ca}^{2+}$ & $\mathrm{Cl}^{-}$ & $\mathrm{SO}_{4}{ }^{2-}$ & $\mathrm{HCO}_{3}^{-}$ & $\mathrm{CO}_{3}{ }^{2-}$ & $\mathrm{NO}_{3}{ }^{-}$ \\
\hline Min & 27.0 & 6.90 & 809.0 & 12.8 & 122.0 & 36.7 & 46.4 & 133.2 & 177.8 & 201.8 & N.D. & 3.5 \\
\hline $\operatorname{Max}$ & 33.7 & 8.90 & 6506.0 & 148.0 & 1500.0 & 220.3 & 524.0 & 1945.2 & 2500.0 & 532.6 & N.D. & 178.8 \\
\hline Mean & 30.0 & 7.77 & 2586.1 & 37.6 & 471.7 & 95.9 & 215.6 & 680.1 & 678.0 & 354.1 & N.D. & 56.9 \\
\hline SD & 2.4 & 0.62 & 1973.5 & 34.4 & 472.2 & 49.5 & 159.1 & 580.3 & 690.1 & 91.7 & N.D. & 46.8 \\
\hline \multicolumn{13}{|c|}{ Central Nile Delta (CND, $n=25)$} \\
\hline Min & 27.1 & 7.45 & 280.0 & 5.0 & 30.0 & 4.8 & 32.0 & 50.0 & 25.0 & 88.0 & N.D. & 0.01 \\
\hline $\operatorname{Max}$ & 28.1 & 7.93 & 910.0 & 7.0 & 86.0 & 52.8 & 152.0 & 240.0 & 120.0 & 320.0 & 80 & 86.0 \\
\hline Mean & 27.43 & 7.75 & 538.8 & 6.3 & 59.8 & 22.8 & 84.5 & 104.0 & 64.7 & 222.8 & 14.76 & 3.80 \\
\hline SD & 0.28 & 0.13 & 194.2 & 0.6 & 16.4 & 11.4 & 40.2 & 40.6 & 31.6 & 63.2 & 22.52 & 17.13 \\
\hline \multicolumn{13}{|c|}{ Data across two regions $(n=40)$} \\
\hline Min & 27.0 & 6.90 & 280.0 & 5.0 & & 4.8 & 32.0 & 50.0 & 25.0 & 88.0 & N.D. & 0.01 \\
\hline $\operatorname{Max}$ & 33.7 & 8.90 & 6506.0 & 148.0 & 1500.0 & 220.3 & 524.0 & 1945.2 & 2500.0 & 532.6 & 80.0 & 178.8 \\
\hline Mean & 28.4 & 7.76 & 1306.5 & 18.0 & 214.2 & 50.2 & 133.6 & 320.1 & 294.7 & 272.0 & 9.0 & 23.7 \\
\hline SD & 1.9 & 0.39 & 1558.5 & 25.7 & 347.8 & 47.4 & 119.2 & 449.1 & 511.8 & 98.1 & 19.0 & 40.6 \\
\hline
\end{tabular}

In general, the groundwater samples of the WD exhibited higher values for all IWQIs than the CND, with the exception of IWQ, which showed the reverse (Table 4). The mean values of IWQ, $\% \mathrm{Na}$, SAR, SSP, PS, and KI across two regions were 76.1, 40.3, 3.67, 36.21, 6.59, and 0.74, respectively (Table 4).

Table 4. Minimum (Min), maximum (Max), mean, and standard deviation (SD) of the different irrigation water quality indicators (IWQIs): irrigation water quality (IWQ), percent sodium (\%Na), sodium absorption ratio (SAR), soluble sodium percentage (SSP), potential salinity (PS), and Kelly's index (KI) in the Western Desert and Central Nile Delta.

\begin{tabular}{|c|c|c|c|c|c|c|}
\hline & \multicolumn{6}{|c|}{ IWQIs } \\
\hline & IWQ & $\% \mathrm{Na}$ & SAR & SSP & PS & KI \\
\hline \multicolumn{7}{|c|}{ El Fayoum Depression, Western Desert (WD, $n=15)$} \\
\hline Min & 28.00 & 36.36 & 2.57 & 34.51 & 1.80 & 0.53 \\
\hline Max & 81.41 & 69.59 & 16.80 & 68.38 & 28.22 & 2.16 \\
\hline Mean & 52.01 & 51.98 & 7.16 & 48.23 & 13.88 & 1.15 \\
\hline SD & 15.37 & 11.44 & 5.09 & 13.44 & 8.82 & 0.53 \\
\hline \multicolumn{7}{|c|}{ Central Nile Delta $(C N D, n=25)$} \\
\hline Min & 80.48 & 25.73 & 0.59 & 21.38 & 1.00 & 0.14 \\
\hline $\operatorname{Max}$ & 99.28 & 38.13 & 2.62 & 36.53 & 5.93 & 1.04 \\
\hline Mean & 90.47 & 33.32 & 1.58 & 28.99 & 2.21 & 0.50 \\
\hline SD & 6.62 & 2.95 & 0.43 & 4.36 & 1.01 & 0.22 \\
\hline \multicolumn{7}{|c|}{ Data across two regions $(n=40)$} \\
\hline Min & 28.00 & 25.73 & 0.59 & 21.38 & 1.00 & 0.14 \\
\hline $\operatorname{Max}$ & 99.28 & 69.59 & 16.80 & 68.38 & 28.22 & 2.16 \\
\hline Mean & 76.05 & 40.32 & 3.67 & 36.20 & 6.59 & 0.74 \\
\hline SD & 21.62 & 11.66 & 4.11 & 12.87 & 7.82 & 0.48 \\
\hline
\end{tabular}


Figures 2 and 3 show the variation in hydrochemical facies of groundwater samples in both regions based on Piper's tri-linear diagram and Chadha's plot. The diamond-shaped field in Piper's diagram shows that the groundwater in both regions was classified into six water types: (1) Ca- $\mathrm{HCO}_{3}$, (2) $\mathrm{Na}-\mathrm{Cl}$, (3) mixed $\mathrm{Ca}-\mathrm{Mg}-\mathrm{Cl}$, (4) Na-Ca- $\mathrm{HCO}_{3}$, (5) $\mathrm{Ca}-\mathrm{Cl}$, and (6) mixed $\mathrm{Na}-\mathrm{HCO}_{3}$. However, most of the groundwater samples from the WD fall into the 2nd and 3rd types, and the samples from the CND fall into the 1st and 3rd types (Figure 2). From Chadha's plot (Figure 3), it can be seen that most of the groundwater samples from the WD were found in field 2, which represents the $\mathrm{Ca}-\mathrm{Mg}-\mathrm{SO}_{4} / \mathrm{Cl}$ type of reverse ion exchange water. While, most of the groundwater samples from the CND, we found in fields 1 and 2, which indicates $\mathrm{Ca}-\mathrm{Mg}-\mathrm{HCO}_{3}$ type water recharging and $\mathrm{Ca}-\mathrm{Mg}-\mathrm{SO}_{4} / \mathrm{Cl}$ type reverse ion exchange water, respectively. Few of the groundwater samples from both regions were found in fields 3 and 4, which indicate $\mathrm{Na}-\mathrm{Cl}$ type salt water and $\mathrm{Na}-\mathrm{HCO} 3$ type base ion-exchange water, respectively (Figure 3).

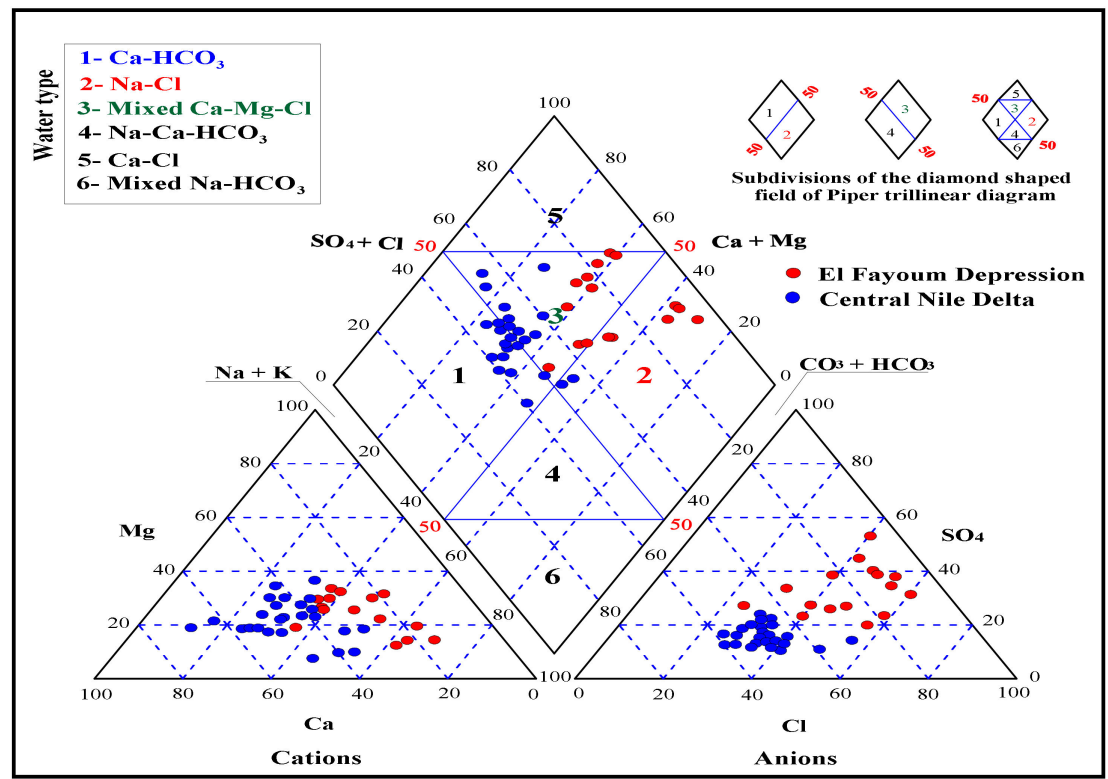

Figure 2. Hydrochemical facies of groundwater samples in the Western Desert and Central Nile Delta based on Piper's tri-linear diagram.

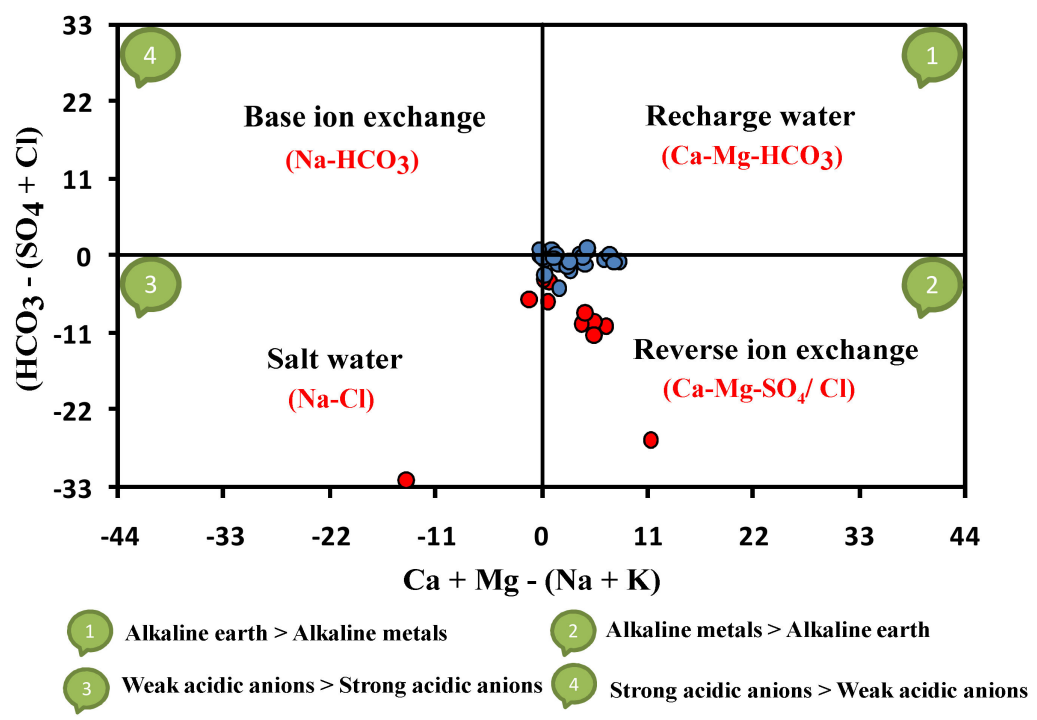

Figure 3. Hydrochemical facies of groundwater samples in the Western Desert and Central Nile Delta based on Chadha's plot. 


\subsection{Classification of Groundwater Quality Based on Different Irrigation Water Quality Indicators}

Based on IWQ, $45.0 \%$ of the groundwater samples, which were all from the CND, were categorized as no restriction and $20.0 \%$ of the samples, of which only one was from the $\mathrm{WD}$, were categorized as low restriction while $5.0 \%$ and $12.0 \%$ of the samples, which were both from the WD, were categorized as high restriction and severe restriction, respectively (Table 5). In addition, a reasonable number (17.5\%) of the groundwater samples, which were all from the WD, fell in the moderate restriction category.

Table 5. Classification of groundwater quality based on different irrigation water quality indicators (IWQIs): irrigation water quality (IWQ), percent sodium (\%Na), sodium absorption ratio (SAR), soluble sodium percentage (SSP), potential salinity (PS), and Kelly's index (KI) in the Western Desert (WD), Central Nile Delta (CND), and across two regions.

\begin{tabular}{|c|c|c|c|c|c|c|}
\hline \multirow{2}{*}{ IWQIs } & \multirow{2}{*}{ Ranges } & \multirow{2}{*}{ Water Quality Class } & \multicolumn{3}{|c|}{ Number of Samples (Percent) } & \multirow{2}{*}{ Reference } \\
\hline & & & First Region & $\begin{array}{l}\text { Second } \\
\text { Region }\end{array}$ & $\begin{array}{l}\text { Across Two } \\
\text { Regions }\end{array}$ & \\
\hline \multirow{5}{*}{ IWQ } & $85-100$ & No restriction & - & $18(72.0 \%)$ & $18(45.0 \%)$ & \multirow{5}{*}{ [6] } \\
\hline & $70-85$ & Low restriction & $1(6.7 \%)$ & $7(28.0 \%)$ & $8(20.0 \%)$ & \\
\hline & $55-70$ & Moderate restriction & $7(46.7 \%)$ & - & $7(17.5 \%)$ & \\
\hline & $40-55$ & High restriction & $2(13.3 \%)$ & - & $2(5.0 \%)$ & \\
\hline & $0-40$ & Severe restriction & $5(33.3)$ & - & $5(12.5 \%)$ & \\
\hline \multirow{5}{*}{$\% \mathrm{Na}$} & $<20$ & Excellent & - & - & - & \multirow{5}{*}{ [36] } \\
\hline & $20-40$ & Good & $4(26.7 \%)$ & $25(100.0 \%)$ & $29(72.5 \%)$ & \\
\hline & $40-60$ & Permissible & $5(33.3 \%)$ & - & $5(12.5 \%)$ & \\
\hline & $60-80$ & Doubtful & $6(40.0 \%)$ & - & $6(15.0 \%)$ & \\
\hline & $>80$ & Unsuitable & - & - & - & \\
\hline \multirow{4}{*}{ SAR } & $<10$ & Excellent & $9(60.0 \%)$ & $25(100.0 \%)$ & $34(85.0 \%)$ & \multirow{4}{*}{ [37] } \\
\hline & $10-18$ & Good/Safe & $6(40.0 \%)$ & - & $6(15.0 \%)$ & \\
\hline & $18-26$ & Doubtful/Moderate & - & - & - & \\
\hline & $>26$ & Unsuitable & - & - & - & \\
\hline \multirow{5}{*}{ SSP } & $0-20$ & Excellent & - & - & - & \multirow{5}{*}{ [36] } \\
\hline & $20-40$ & Good & $7(46.7 \%)$ & $25(100.0 \%)$ & $32(80.0 \%)$ & \\
\hline & $40-60$ & Permissible & $3(20.0 \%)$ & - & $3(7.5 \%)$ & \\
\hline & $60-80$ & Doubtful & $5(33.3 \%)$ & - & $5(12.5 \%)$ & \\
\hline & 80-100 & Unsuitable & - & - & - & \\
\hline \multirow{3}{*}{ PS } & $<3$ & Excellent to Good & $1(6.7 \%)$ & $21(84.0 \%)$ & $22(55.0 \%)$ & \multirow{3}{*}{ [38] } \\
\hline & $3-5$ & Good to Injurious & - & $3(12.0 \%)$ & $3(7.5 \%)$ & \\
\hline & $>5$ & Injurious to Unsatisfactory & $14(93.3)$ & $1(4.0 \%)$ & $15(37.5 \%)$ & \\
\hline \multirow{2}{*}{ KI } & $<1$ & Suitable & $8(53.3 \%)$ & $24(96.0 \%)$ & $32(80.0 \%)$ & \multirow{2}{*}{ [39] } \\
\hline & $>1$ & Unsuitable & $7(46.7 \%)$ & $1(4.0 \%)$ & $8(20.0 \%)$ & \\
\hline
\end{tabular}

Based on different parameters related to $\mathrm{Na}$ ions, such as \%Na, SAR, and SSP, the majority of the groundwater samples were classified as excellent to good. About $72.5 \%, 85.0 \%$, and $80.0 \%$ of the total groundwater samples, which were mostly from the CND, were classified as good, excellent, and good for irrigation purposes based on $\% \mathrm{Na}$, SAR, and SSP, respectively.

Based on the three parameters, $7.5-15.0 \%$ of groundwater samples were only classified as permissible or safe, and they were all from the WD. None of the samples were classified as unsuitable, based on the three parameters. However, $15.0 \%$ and $12.5 \%$ of the groundwater samples, which were both from the WD, were classified as doubtful based on \%Na and SSP, respectively (Table 5).

Although there was a sufficient number $(55.0 \%)$ of groundwater samples which were mostly from the CND, that were classified as excellent to good based on PS, unfortunately, there were still a reasonable number of groundwater samples (37.5\%), which were mostly from the WD, that were classified as injurious to unsatisfactory (Table 5). Interestingly, the KR indicated that $80 \%$ of the total groundwater samples, of which 53.3\% were from the WD and $96.0 \%$ were from the CND, were less 
than one and thereby suitable for irrigation purposes. Only $20 \%$ of the total groundwater samples, of which only $4.0 \%$ were from the CND, were unsuitable for irrigation (Table 5).

\subsection{Relationships between Different Irrigation Water Quality Indicators and Spectral Reflectance Data}

Several contour maps, which were based on linear, quadratic, and exponential equations, were established to show the values of coefficients of determination $\left(R^{2}\right)$ between all dual wavelength combinations in the range of $302-1148 \mathrm{~nm}$ as an SRI and each of the IWQIs (Figure 4). The different contour maps were developed based on the spectral reflectance data of all the collected groundwater samples $(n=40)$. In general, based on the $\mathbf{R}^{2}$ values of the contour maps, there were three hotspot regions for the best $R^{2}$, which were located at different wavelength intervals: $312-360 \mathrm{~nm}$ on the horizontal axis and $370-900 \mathrm{~nm}$ on the vertical axis, $317-354 \mathrm{~nm}$ on the horizontal axis and 1054-1148 $\mathrm{nm}$ on the vertical axis, and 700-920 nm on the horizontal axis and $932-1030 \mathrm{~nm}$ on the vertical axis (white and yellow color in Figure 4). Therefore, the SRIs that were developed in this study and showed strong relationships with the different IWQIs were based on UV/VIS, UV/NIR, VIS/VIS, VIS/NIR, and NIR/NIR.
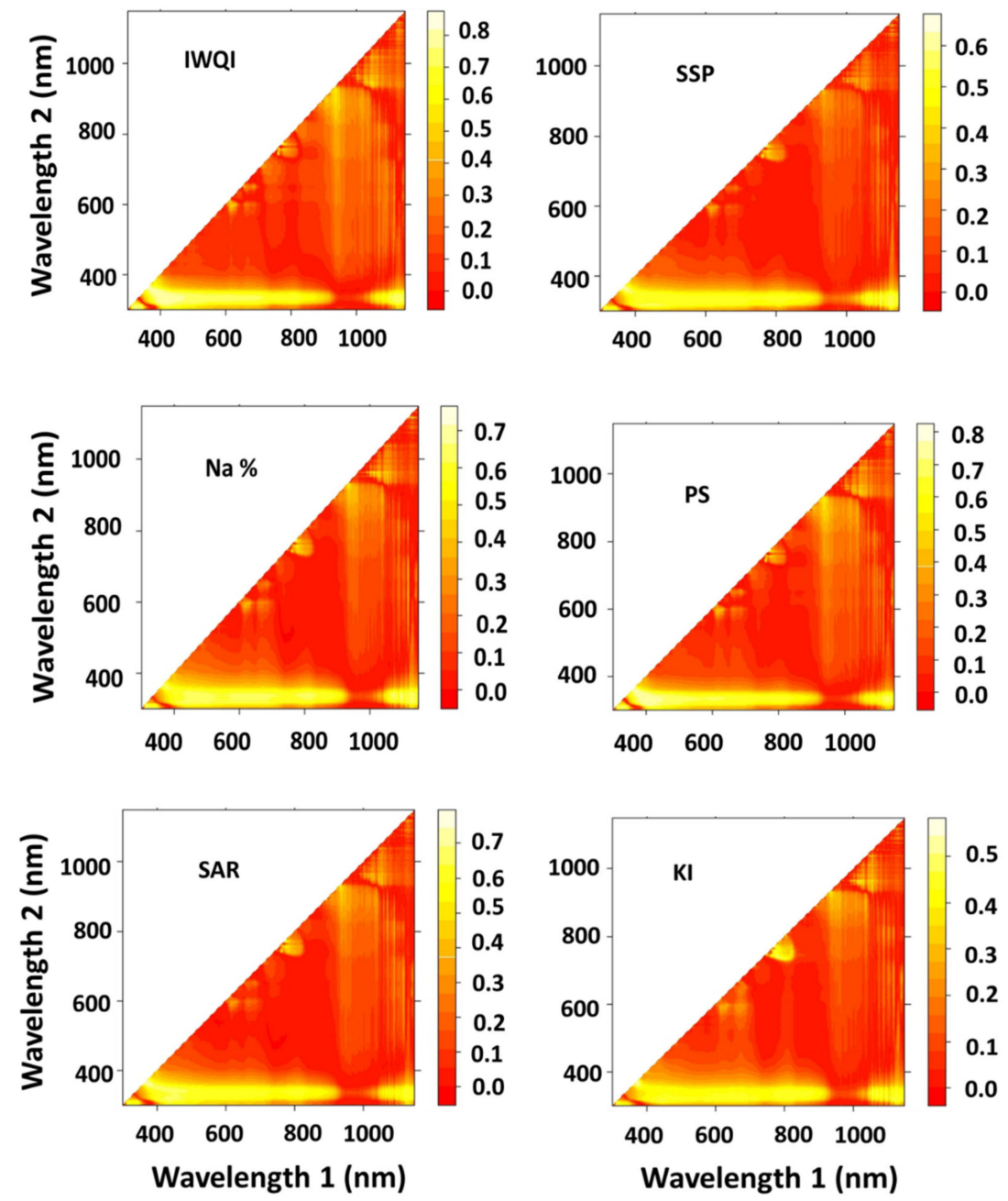

Figure 4. Contour maps of coefficients of determination $\left(\mathrm{R}^{2}\right)$ between all dual wavelength combinations in the range of 302-1148 $\mathrm{nm}$ as a spectral ratio index and each of the irrigation water quality indicators (IWQIs): irrigation water quality (IWQ), percent sodium (\%Na), sodium absorption ratio (SAR), soluble sodium percentage (SSP), potential salinity (PS), and Kelly's index (KI). The contour maps were established based on the combined spectral reflectance data of groundwater samples from two regions $(n=40)$. 


\subsection{Variability of Spectral Reflectance Indices among Groundwater Samples}

In general, the minimum and maximum values for SRIs were higher in the WD than the CND (Table 6). However, in each region and across two regions, there was a wide range between the maximum and minimum values for all tested SRIs, with the exception of $R_{596} / R_{630}, R_{622} / R_{594}$, and $R_{776} / R_{770}$, which showed a narrow range between the maximum and minimum values among groundwater samples. For the other SRIs, the maximum values exceed the minimum values by $1.5-2.5$ times (Table 6), indicating broad variability for spectral indices among different groundwater samples.

Table 6. Minimum (min), maximum (max), and mean ( \pm standard deviations (SD)) values of different spectral reflectance indices (SRIs) for groundwater samples of the Western Desert and Central Nile Delta.

\begin{tabular}{|c|c|c|c|c|c|c|c|c|c|}
\hline \multirow{2}{*}{ SRIs } & \multicolumn{3}{|c|}{ Western Desert $(n=15)$} & \multicolumn{3}{|c|}{ Central Nile Delta $(n=25)$} & \multicolumn{3}{|c|}{$\begin{array}{l}\text { Data across Two } \\
\text { Regions }(n=40)\end{array}$} \\
\hline & Min & Max & Mean $( \pm$ SD) & Min & Max & Mean $( \pm$ SD) & Min & Max & Mean $( \pm$ SD) \\
\hline $\mathbf{R}_{326} / \mathbf{R}_{1106}$ & 0.39 & 0.89 & $0.75 \pm 0.116$ & 0.37 & 0.52 & $0.45 \pm 0.040$ & 0.37 & 0.89 & $0.56 \pm 0.165$ \\
\hline $\mathbf{R}_{330} / \mathbf{R}_{456}$ & 0.66 & 0.92 & $0.78 \pm 0.076$ & 0.53 & 0.85 & $0.66 \pm 0.076$ & 0.53 & 0.92 & $0.70 \pm 0.096$ \\
\hline $\mathbf{R}_{332} / \mathbf{R}_{1106}$ & 0.40 & 0.85 & $0.72 \pm 0.107$ & 0.34 & 0.53 & $0.42 \pm 0.042$ & 0.34 & 0.85 & $0.53 \pm 0.164$ \\
\hline $\mathbf{R}_{334} / \mathbf{R}_{550}$ & 0.28 & 0.57 & $0.49 \pm 0.066$ & 0.21 & 0.43 & $0.26 \pm 0.042$ & 0.21 & 0.57 & $0.35 \pm 0.123$ \\
\hline $\mathbf{R}_{334} / \mathbf{R}_{1100}$ & 0.47 & 0.93 & $0.82 \pm 0.108$ & 0.39 & 0.59 & $0.48 \pm 0.054$ & 0.39 & 0.93 & $0.61 \pm 0.182$ \\
\hline $\mathbf{R}_{334} / \mathbf{R}_{670}$ & 0.28 & 0.65 & $0.55 \pm 0.082$ & 0.23 & 0.45 & $0.29 \pm 0.043$ & 0.23 & 0.65 & $0.39 \pm 0.141$ \\
\hline $\mathbf{R}_{338} / \mathbf{R}_{670}$ & 0.29 & 0.64 & $0.55 \pm 0.080$ & 0.23 & 0.46 & $0.29 \pm 0.044$ & 0.23 & 0.64 & $0.40 \pm 0.140$ \\
\hline $\mathbf{R}_{596} / \mathbf{R}_{630}$ & 1.01 & 1.04 & $1.03 \pm 0.007$ & 1.01 & 1.03 & $1.02 \pm 0.006$ & 1.01 & 1.04 & $1.02 \pm 0.009$ \\
\hline $\mathbf{R}_{622} / \mathbf{R}_{594}$ & 0.97 & 0.99 & $0.98 \pm 0.006$ & 0.98 & 1.00 & $0.99 \pm 0.006$ & 0.97 & 1.00 & $0.98 \pm 0.008$ \\
\hline $\mathbf{R}_{776} / \mathbf{R}_{770}$ & 1.00 & 1.01 & $1.00 \pm 0.001$ & 1.00 & 1.02 & $1.01 \pm 0.002$ & 1.00 & 1.02 & $1.01 \pm 0.004$ \\
\hline WI & 0.60 & 0.89 & $0.81 \pm 0.068$ & 0.74 & 0.95 & $0.82 \pm 0.043$ & 0.60 & 0.95 & $0.81 \pm 0.053$ \\
\hline NWI-3 & -0.65 & -0.39 & $-0.50 \pm 0.062$ & -0.70 & -0.24 & $-0.62 \pm 0.083$ & -0.70 & -0.24 & $-0.57 \pm 0.094$ \\
\hline $\mathbf{R}_{359} / \mathbf{R}_{675}$ & 0.37 & 0.91 & $0.75 \pm 0.130$ & 0.35 & 0.62 & $0.48 \pm 0.72$ & 0.35 & 0.91 & $0.58 \pm 0.162$ \\
\hline $\mathbf{R}_{359} / \mathbf{R}_{854}$ & 0.53 & 1.66 & $1.40 \pm 0.289$ & 0.69 & 1.23 & $0.96 \pm 0.137$ & 0.53 & 1.66 & $1.12 \pm 0.297$ \\
\hline
\end{tabular}

3.5. Association of Simple Reflectance Indices with Different Physicochemical Parameters and Irrigation Water Quality Indicators

In general, the SRIs correlated better with the different parameters related to groundwater quality when they were calculated using the spectral reflectance data detected from groundwater samples from the WD ( $\mathrm{r}$ ranged from 0.01 to 0.76 ; Figure 5) compared with those detected from groundwater samples from the CND (r ranged from 0.01 to 0.60; Figure 6). Importantly, the Pearson's correlation coefficients between the SRIs and parameters related to groundwater quality increased when the spectral reflectance data of the groundwater samples of two regions were combined ( $\mathrm{r}$ ranged from 0.01 to 0.88 ; Figure 7 ). All SRIs developed in this study exhibited moderate correlations with IWQIs in the WD ( $\mathrm{r}$ ranged from 0.15 to 0.67 ) and moderate to strong correlation with IWQIs across two regions ( $\mathrm{r}$ ranged from 0.46 to 0.88 ), with the exception of SRI based on NIR/NIR $\left(R_{950} / R_{970}\right)$, which failed to correlate with any of the IWQIs. The two published SRIs $\left(R_{359} / R_{675}\right.$ and $\left.R_{359} / R_{854}\right)$, which were based on UV/VIS and UV/NIR, respectively, and exhibited strong correlations with the WQI of drinking water in a previous study, exhibited moderate correlations with IWQIs in this study ( $\mathrm{r}$ ranged from 0.47 to 0.67) when the spectral reflectance data of groundwater samples of the two regions were combined (Figure 7). Both SRIs (developed in this study and published) exhibited weak Correlations with \% $\mathrm{Na}$ and PS in the WD (r ranged from 0.17 to 0.22; Figure 5) and a moderate correlation with PS in the CND ( $\mathrm{r}$ ranged from -0.35 to -0.38 ; Figure 6 ). The published normalized water index-3, which is based on two wavelengths from NIR region ( 970 and $880 \mathrm{~nm}$ ), exhibited weak to moderate correlation with IWQIs from the WD ( $\mathrm{r}$ ranged from 0.18 to -0.41 ), moderate correlation with the IWQIs across two regions ( $\mathrm{r}$ ranged from 0.42 to -0.58$)$, and moderate correlation with the SSP from the CND $(\mathrm{r}=-0.31)$. 


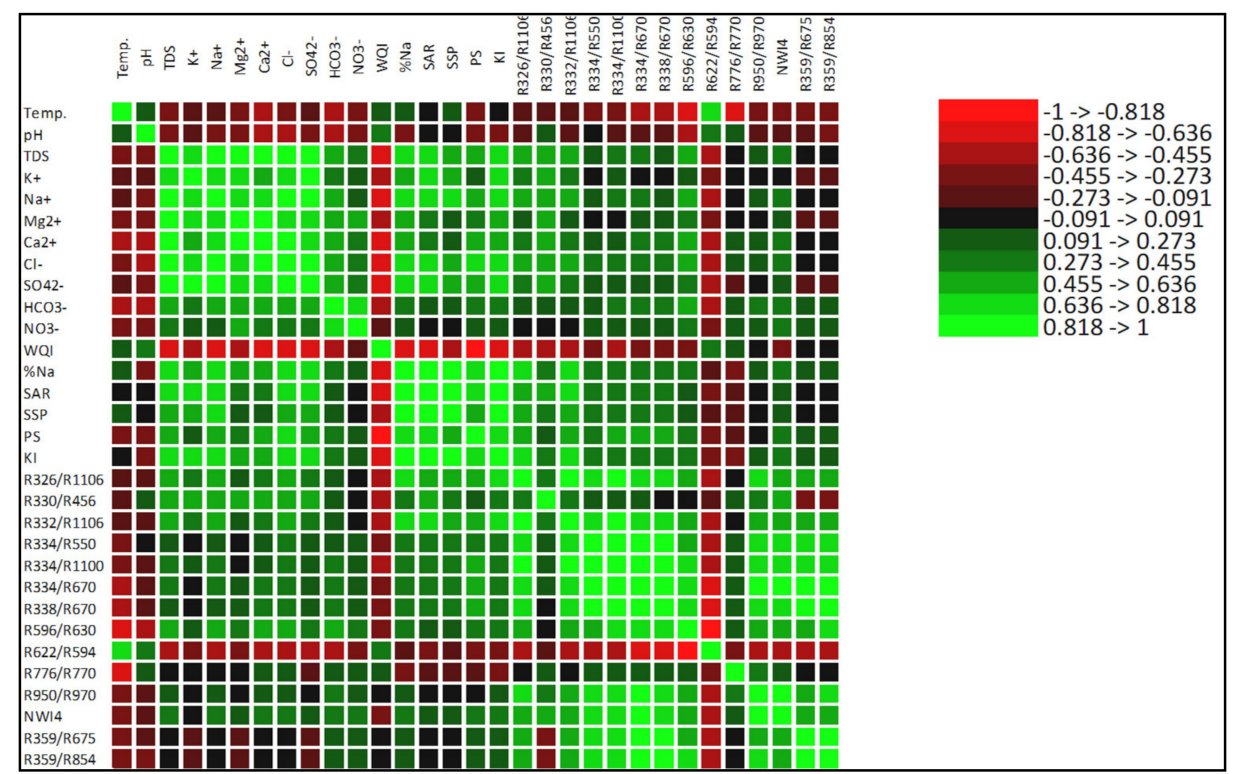

Figure 5. Correlation matrix of spectral reflectance indices with physicochemical parameters and irrigation water quality indicators: irrigation water quality (IWQ), percent sodium (\%Na), sodium absorption ratio (SAR), soluble sodium percentage (SSP), potential salinity (PS), and Kelly's index (KI) in the Western Desert $(n=15)$.

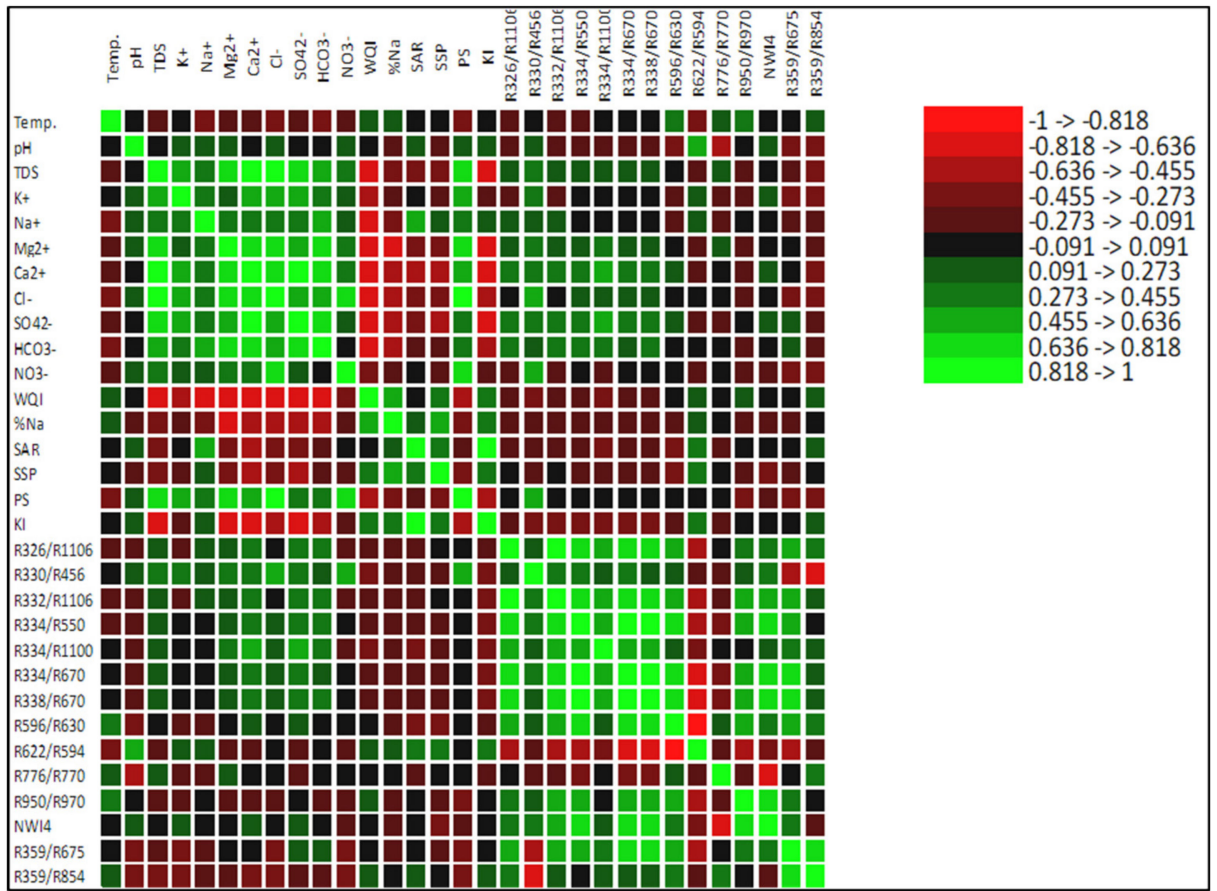

Figure 6. Correlation matrix of spectral reflectance indices with physicochemical parameters and irrigation water quality indicators: irrigation water quality (IWQ), percent sodium (\%Na), sodium absorption ratio (SAR), soluble sodium percentage (SSP), potential salinity (PS), and Kelly's index (KI) in the Central Nile Delta $(n=25)$. 


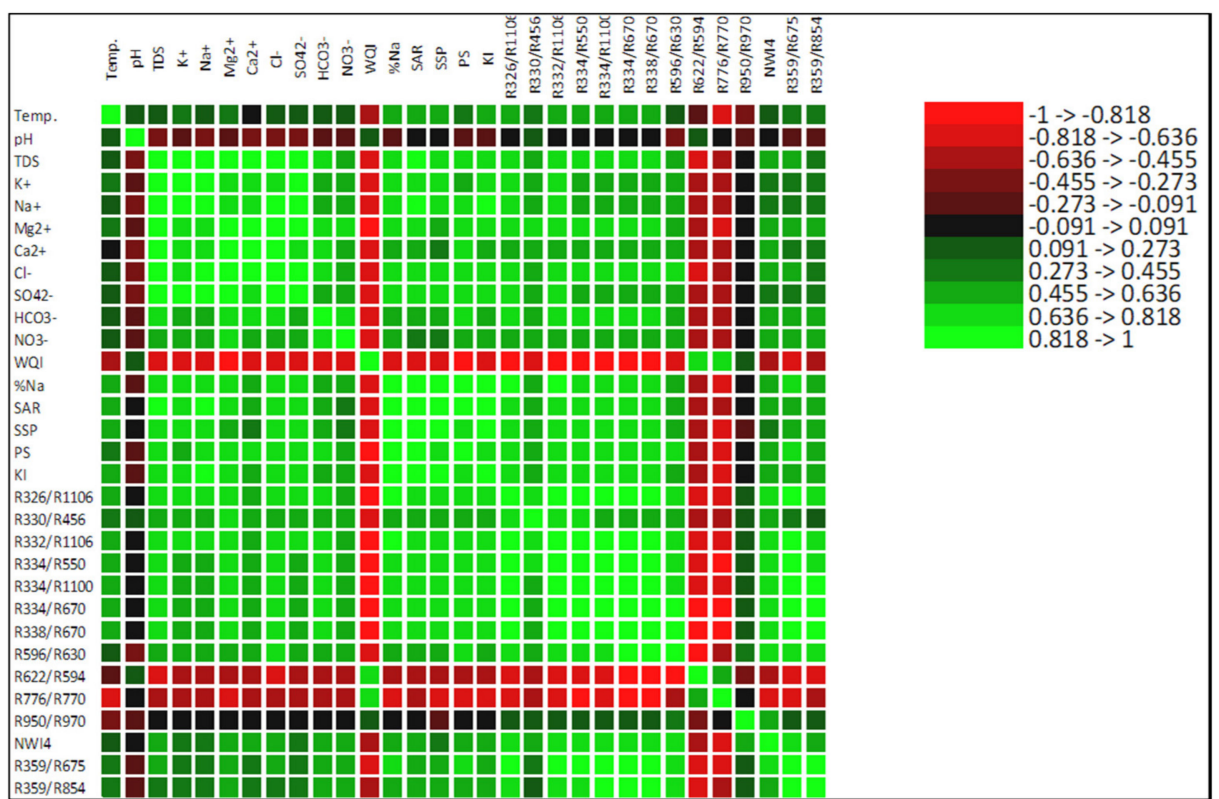

Figure 7. Correlation matrix of spectral reflectance indices with physicochemical parameters and irrigation water quality indicators: irrigation water quality (IWQ), percent sodium (\%Na), sodium absorption ratio (SAR), soluble sodium percentage (SSP), potential salinity (PS), and Kelly's index (KI) across the Western Desert and Central Nile Delta $(n=40)$.

\subsection{Precision of Different Parameters of Irrigation Water Quality Indicators Using Partial Least Square} Regression

Table 7 summarizes the coefficient of determination $\left(R^{2}\right)$ and corresponding root mean squared error (RMSE), and slope of the calibration (Cal.) and validation (Val.) datasets of the PLSR models to estimate different parameters related to IWQIs based on the full-spectrum ranges (302-1148 nm). The performance of the PLSR models for estimating the IWQIs was based on the groundwater samples across two regions $(n=40)$. In general, based on values of $R^{2}$ and slope, the PLSR model provided a more accurate estimation of IWQ and \%Na than other parameters of IWQIs in both the Cal. and Val. datasets. In addition, the PLSR model provided accurate estimations of IWQ and \% $\mathrm{Na}$ in the Cal. datasets with $\mathrm{R}^{2}$ cal of 0.70 and 0.79 and $\mathrm{RMSE}_{\mathrm{Cal}}$ of 11.60 and 5.23, respectively (Table 7). However, the PLSR model generated a moderate estimation performance for other IWQIs (SAR, SSP, PS, and KI) in the Cal. datasets $\left(R^{2}\right.$ cal ranged from 0.39 to 0.50$)$ and all IWQIs in the Val. dataset $\left(R^{2}\right.$ val ranged from 0.32 to 0.60 ) (Table 7).

Figure 8 shows the coefficient of determination $\left(\mathrm{R}^{2}\right)$ and corresponding root mean squared error (RMSE), and slope of the calibration (Cal.) and validation (Val.) datasets of the PLSR models based on all SRIs as well as linear relationships between the calculated and predicted values for each IWQI. In general, the PLSR models based on all SRIs provided a more accurate estimation of different IWQIs in both the Cal. and Val. datasets $\left(\mathrm{R}^{2}\right.$ ranged from 0.66 to 0.82 in the Cal. and from 0.54 to 0.77 in the Val.; Figure 8) than those PLSR models that were based on the full-spectrum ranges of $302-1148 \mathrm{~nm}$. $\left(R^{2}\right.$ ranged from 0.39 to 0.79 in the Cal. and from 0.32 to 0.60 in the Val.; Table 7). In addition, they provided a good relationship between calculated and predicted values for all parameters of IWQIs in the Cal. datasets $\left(R^{2}\right.$ cal. ranged from 0.66 to 0.82$)$ and IWQ and \%Na in the Val. datasets $\left(R^{2}\right.$ val. $=0.77$ and 0.70 , respectively), whereas they showed a moderate relationship between calculated and predicted values for SAR, SSP, PS, and KI in the Val. datasets $\left(\mathrm{R}^{2}\right.$ val. $=0.60,0.63,0.54$, and 0.54 , respectively) (Figure 8$)$. 
Table 7. Coefficient of determination $\left(\mathrm{R}^{2}\right)$, root mean squared error (RMSE), and regression equation (Eq) for calibration $\left(\mathrm{R}^{2}{ }_{\mathrm{cal}}, \mathrm{RMSE}_{\mathrm{Cal}}\right.$, and $\left.\mathrm{Eq}_{\mathrm{cal}}\right)$ and validation $\left(\mathrm{R}_{\mathrm{val}}^{2}, \mathrm{RMSE}_{\mathrm{Val}}\right.$, and $\left.\mathrm{Eq}_{\mathrm{val}}\right)$ statistics of partial least squares regression (PLSR) models based on the full-spectrum ranges (302-1148 nm) for the assessment of different irrigation water quality indicators (IWQIs): irrigation water quality (IWQ), percent sodium $(\% \mathrm{Na})$, sodium absorption ratio (SAR), soluble sodium percentage (SSP), potential salinity (PS), and Kelly's index (KI). Estimates were calculated across the Western Desert and Central Nile Delta $(n=40)$.

\begin{tabular}{|c|c|c|c|c|c|c|c|}
\hline \multirow{2}{*}{ IWQIs } & \multirow{2}{*}{ PCs } & \multicolumn{3}{|c|}{ Calibration Dataset } & \multicolumn{3}{|c|}{ Validation Dataset } \\
\hline & & $\mathbf{R}_{\text {cal }}^{2}$ & RMSE $_{\text {Cal }}$ & $\mathrm{Eq}_{\mathrm{cal}}$ & $\mathbf{R}_{\text {val }}^{2}$ & RMSEV $_{\mathrm{V}}$ & $\mathrm{Eq}_{\mathrm{val}}$ \\
\hline IWQ & 2 & $\begin{array}{c}0.70 \\
* * *\end{array}$ & 11.60 & $y=0.7045 x+22.475$ & $0.60 * *$ & 13.81 & $y=0.6625 x+26.502$ \\
\hline$\% \mathrm{Na}$ & 5 & $\begin{array}{c}0.79 \\
* * *\end{array}$ & 5.23 & $y=0.7936 x+8.3204$ & $0.57^{* *}$ & 7.75 & $y=0.6068 x+16.323$ \\
\hline SAR & 2 & 0.44 * & 3.04 & $y=0.4391 x+2.0589$ & $0.37 *$ & 3.33 & $y=0.3885 x+2.1383$ \\
\hline SSP & 2 & $\underset{* *}{0.50}$ & 9.02 & $y=0.4959 x+18.249$ & $0.42 *$ & 9.87 & $y=0.4605 x+19.34$ \\
\hline PS & 5 & 0.49 * & 5.49 & $y=0.4944 x+3.3304$ & $0.40 *$ & 6.12 & $y=0.4527 x+3.4935$ \\
\hline KI & 2 & 0.39 * & 0.37 & $y=0.39 x+0.452$ & $0.32 *$ & 0.40 & $y=0.3507 x+0.4711$ \\
\hline
\end{tabular}

$*, * *, * * *$ indicate statistical significance at the $0.05,0.01$, and 0.001 probability levels, respectively. PCs indicates Number of Latent Variables
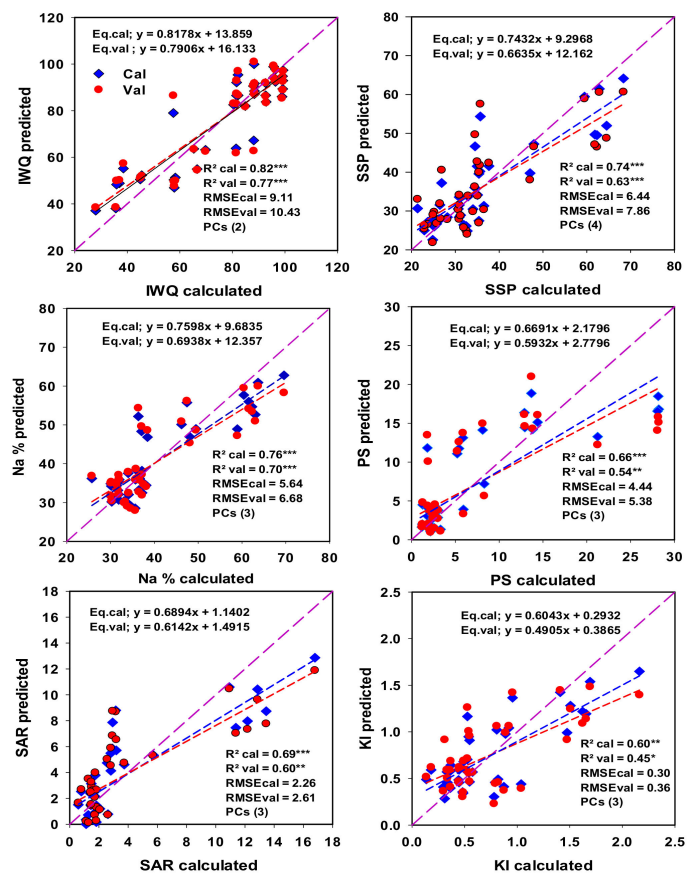

Figure 8. Coefficient of determination $\left(\mathrm{R}^{2}\right)$, root mean squared error (RMSE), and equation (Eq) for calibration $\left(\mathrm{R}^{2}\right.$ cal, $\mathrm{RMSE} \mathrm{Cal}_{\mathrm{C}}$, and $\left.\mathrm{Eq}_{\mathrm{cal}}\right)$ and validation $\left(\mathrm{R}_{\mathrm{val}}, \mathrm{RMSE}_{\mathrm{Val}}\right.$, and $\left.\mathrm{Eq}_{\mathrm{val}}\right)$ of the relationship between calculated and predicted values of different irrigation water quality indicators (IWQIs): irrigation water quality (IWQ), percent sodium (\%Na), sodium absorption ratio (SAR), soluble sodium percentage (SSP), potential salinity (PS), and Kelly's index (KI) of partial least squares regression (PLSR) models based on fourteen different spectral reflectance indices (SRIs). Estimates were calculated across the Western Desert and Central Nile Delta $(n=40) .^{*},{ }^{* *},{ }^{* * *}$ indicate statistical significance at the 0.05, 0.01 , and 0.001 probability levels, respectively. PCs indicate number of latent variables. 


\section{Discussion}

4.1. Assessment of Groundwater Quality for Irrigation Purposes Based on Physicochemical Parameters, Irrigation Water Quality Indicators, and Hydrochemical Facies

The IWQ provides a single value that reflects the overall quality levels of groundwater for either drinking or irrigation purposes through five categories ranging from 0 (very poor water quality) to 100 (excellent water quality) $[3,6,40,47,48]$. In this study, the mean value of IWQ ranged from 28.0 to 81.4 and 80.5 to 99.3 for the El Fayoum depression in the Western Desert and the Central Nile Delta, respectively (Table 4). In addition, the data in Table 5 indicated that $45.0 \%$ and $20 \%$ of the total groundwater samples were categorized as no and low restriction, respectively, with only $12.5 \%$ of the total samples categorized as unsuitable. These results indicate that most of the groundwater samples from both regions of this study are suitable for irrigation purposes and human consumption, as long as the water is treated, particularly in the WD.

In general, excessive concentrations of $\mathrm{Na}^{+}$in irrigation water results in a significant reduction in soil permeability and aeration, promotes soil dispersion and structural breakdown, makes the soil hard to till, inhibits the absorption of water by plants, and hinders the uptake of essential ions, such as $\mathrm{K}^{+}, \mathrm{Ca}^{2+}$, and $\mathrm{Mg}^{2+}$ [49-52]. Many of these negative impacts of excessive $\mathrm{Na}^{+}$eventually limit the growth and productivity of most field crops [53,54]. Therefore, Na ions represent a common factor in determining several water quality parameter-based indices, such as \%Na, SAR, SSP, and KI, which help classify the suitability of any water source for irrigation purposes. In addition, the assessment of irrigation water quality based on these four IWQIs also depends on the relative $\mathrm{Na}^{+}$concentration to the concentrations of $\mathrm{K}^{+}, \mathrm{Ca}^{2+}$, and $\mathrm{Mg}^{2+}$ (see the formula in Table 1). In this study, $\mathrm{Na}^{+}$exhibited a strong positive correlation ( $\mathrm{r}$ ranged from 0.66 to 0.80 ) while $\mathrm{K}^{+}, \mathrm{Ca}^{2+}$, and $\mathrm{Mg}^{2+}$ exhibited moderate to weak correlations ( $\mathrm{r}$ ranged from 0.19 to 0.67 ) with the four IWQIs in the WD (Figure 5). In the CND, $\mathrm{Na}^{+}$exhibited a moderate to weak correlation ( $\mathrm{r}$ ranged from 0.11 to 0.56 ) while $\mathrm{Ca}^{2+} \mathrm{and}_{\mathrm{Mg}^{2+}}$ exhibited moderate to strong correlations (r ranged from 0.38 to 0.72 ) with the four IWQIs (Figure 6). Therefore, the mean values of the four IWQIs for the groundwater samples from the WD were higher than those from the CND (Table 4$)$. Furthermore, the majority ( 100\%) of the groundwater samples from the CND and $\sim 40-60 \%$ of the groundwater samples from the WD were categorized as excellent to good based on the four IWQIs (Table 5). These results indicate that the groundwater of the CND is suitable for irrigation, while the groundwater of the WD can be used for irrigation but with a good drainage system to control salt accumulation in the soil. The low quality of groundwater in the WD may be attributed to the main sources of the water recharge for the Quaternary aquifer, which is considered the most important aquifer in the El Fayoum depression, being that there is water seepage from excessive surface irrigation and surface irrigation canals and the intrusion of saline water from the underlying fractured limestone of the Eocene aquifer through hydraulic connection [55,56]. In addition, the groundwater of the WD is currently experiencing contamination from heavy agricultural activities, including excessive use of artificial chemical fertilizers and pesticides, reuse of agricultural drainage water for irrigation, and wastewater disposal [57]. However, the groundwater of the CND, which is from the Central Nile Delta aquifer, is regularly replenished directly by Nile River water through water seepage from the two Nile River branches. Therefore, the groundwater of the Nile Delta aquifer, which provides about $85 \%$ of total groundwater abstractions in Egypt (6.1 billion cubic meters per year), is considered another important irrigation water resource after the Nile River [58]. In this study, when the quality of groundwater of both regions was categorized using PS, which is defined as the summation of $\mathrm{Cl}^{-}$and half of the $\mathrm{SO}_{4}{ }^{2-}$ and is a very important index for determining the suitability of groundwater for irrigation purposes [51], 6.7\% and 93.3\% of samples from the WD and $84.0 \%$ and only $4.0 \%$ of samples from the CND were classified as excellent to good and injurious to unsatisfactory class, respectively (Table 5). The results of PS further confirm that the groundwater of the CND is more suitable for irrigation than that from the WD. 
The groundwater composition in different classes can also be determined using hydrochemical facies, which reflect the overall effects of natural chemical processes occurring between rock minerals within aquifers [59]. In this study, Piper's diagram [41] and Chadha's plot [42] were used to interpret the hydrochemical facies of groundwater in both regions (Figs 3 and 4). Based on Piper's diagram, which was drawn by plotting the dominant major cations and anions that affect the hydrochemistry of groundwater in two distinct triangles and a central diamond field, $\mathrm{Na}-\mathrm{Cl}$ was the dominant water type in the groundwater of the WD, while $\mathrm{Ca}-\mathrm{HCO}_{3}$ was the dominant type in the groundwater of the CND. In addition, mixed $\mathrm{Ca}-\mathrm{Mg}-\mathrm{Cl}$ was dominant in both regions (Figs 3). The presence of high $\mathrm{Na}^{+}$and $\mathrm{Cl}^{-}$contents in the groundwater in the WD indicate the dominance of saline intrusions. In the $\mathrm{WD}$, these could be derived from the recharge of the underlying fractured limestone of the Eocene aquifer and the return flow of surface irrigation water $[55,56]$. The finding that most of the samples of the groundwater from the $\mathrm{CND}$ were the $\mathrm{Ca}-\mathrm{HCO} 3$ water type indicates freshwater recharge into the aquifers [60], which aligns with water recharge from the Nile Delta basin [58].

Based on Chadha's plot, the results of this study indicate that most samples of groundwater from the WD were found in field 2, which shows that alkali metals $\left(\mathrm{Na}^{+}+\mathrm{K}^{+}\right)$significantly exceed alkaline earth metals $\left(\mathrm{Ca}^{2+}+\mathrm{Mg}^{2+}\right)$, and field 3, which represents $\mathrm{Na}-\mathrm{Cl}$ type saltwater. However, most the samples of groundwater from the CND were found in field 1, which indicates that alkaline earth metals $\left(\mathrm{Ca}^{2+}+\mathrm{Mg}^{2+}\right)$ significantly exceeded alkali metals $\left(\mathrm{Na}^{+}+\mathrm{K}^{+}\right)$(Figure 4). These results also confirm that the type of water in the WD generally causes salinity problems for usage in irrigation. In addition, the type of water in the CND was fresher than in the CND.

\subsection{Performance of Hyperspectral Reflectance Sensing for In Situ Estimation of Groundwater Quality for Irrigation Use}

To the best of our knowledge, several studies have examined the performance of space-borne optical remote sensing systems for assessing water quality and most of them have only focused on the physical and biological parameters related to water quality, such as turbidity or transparency, and the concentration of chlorophyll-a and colored dissolved organic matters [18,22,24,61-64]. However, there are only a few studies that have conducted in situ estimation of the IWQIs of groundwater using a ground-based hyperspectral system.

As expected, the different physiochemical constituents of water induce significant changes in the characteristics of the light reflected by the water components at different bands of the light spectrum, which can be used to assess and manage groundwater quality. Several studies have reported that the light spectrum in the ranges of the VIS, red-edge, and NIR regions have more robust association with different physiochemical water components in different waterbodies than other parts of spectral regions, and thus, these ranges of the spectrum could be used to quantitatively determine water quality parameters $[12,19,26,30,65-68]$. For instance, Seyhan et al. [65] reported that the spectral signatures in the range of 400-900 $\mathrm{nm}$ of the spectrum are promising and feasible for monitoring of water quality. Wu et al. [67] reported that spectral reflectance of 750-900 $\mathrm{nm}$ is the optimal wavelength range for assessing TSS concentrations. In addition, Wang et al. [12] reported that it is easy to assess drinking water quality at roughly $700-720 \mathrm{~nm}$ and $1070 \mathrm{~nm}$ of the peak. Furthermore, they also found that the spectral reflectance curves for several collected drinking water samples showed several pronounced deep absorption regions at 700, 750, 950, and $980 \mathrm{~nm}$ and several weak absorption regions at approximately 452,703 , and $850 \mathrm{~nm}$. Xing et al. [19] further reported that the wavelength interval from 460 to $480 \mathrm{~nm}$ is effective at estimating five water quality parameters of sewage water (chemical oxygen demand (COD), biological oxygen demand (COD), total dissolved substances (TDS), total hardness (TH), and total alkalinity (TA)), and the wavelength interval from 990 to $999 \mathrm{~nm}$ was identified as the most important region for estimating $\mathrm{NH}_{3}-\mathrm{N}$.

In this study, the different contour maps, which represent the best coefficients of determination $\left(R^{2}\right)$ matrices between different IWQIs and all the possible two-wavelength combinations (as a ratio spectral reflectance indices) in the range of 302-1148 nm, the wavelength intervals from $312-360 \mathrm{~nm}, 317-354 \mathrm{~nm}$, 
and 700-920 $\mathrm{nm}$ on the horizontal axis exhibited highest $\mathrm{R}^{2}$ values with different IWQIs when they were combined with wavelength intervals from $370-900 \mathrm{~nm}, 1054-1148 \mathrm{~nm}$, and $392-1030 \mathrm{~nm}$ on the vertical axis, respectively (Figure 4). This result reveals the importance of the UV, VIS, and NIR spectrum wavelength regions for estimating the IWQIs of groundwater. The different results of SRIs, which were developed as a ratio between the combination of UV/VIS, UV/NIR, VIS/VIS, VIS/NIR, and NIR/NIR, reinforce these findings and show that most of these SRIs exhibited a wide range between the maximum and minimum values, where the maximum values exceeded the minimum values by about 1.5 to 2.5 times (Table 6), indicating broad variability in spectral reflectance characteristics between collected groundwater samples. In addition, most of these SRIs exhibited moderate, weak, and moderate to strong correlation with IWQIs and several physiochemical parameters in the WD (Figure 5), CND (Figure 6), and across both regions (Figure 7), respectively. These findings also support the direct and indirect effects of different water components on the spectral radiation features that are reflected from the water surface, and they reflect the feasibility of SRIs that incorporate wavelengths from UV, VIS, red-edge, and NIR of the spectrum for the assessment and management of groundwater quality for irrigation purposes. However, the problem of a weaker spectral response, which was found in this study with the groundwater samples of the CND, sometimes occurs in the spectral analysis of water components. Most of the tested SRIs showed weak correlation with different IWQIs and measured parameters, with few exceptions (Figure 6), indicating the concentrations of water components may play a distinct role in the estimation of groundwater quality using a hyperspectral approach. The groundwater of the CND is regularly replenished by the Nile River water directly through the seepage of water from the two Nile River branches, while the groundwater of the WD is recharged from the water seepage from excessive surface irrigation and surface irrigation canals, and intrusion of saline water from the underlying fractured limestone of the Eocene aquifer [55,56]. In addition, the groundwater quality of the WD is influenced by anthropogenic activities and the excessive use of fertilizers and pesticides [57]. Therefore, the differences in groundwater quality between the two regions exhibited significant differences in the feasibility of indirect estimation of their quality using a hyperspectral tool. Seyhan et al. [65] also reported that the characteristics of spectral signals received from the water surface are a function of hydrological, biological, and chemical characteristics of water components.

Although the SRIs (in a simple ratio or normalized formula) represent a very simple approach for estimating groundwater quality and can be exploited to develop lightweight spectral sensors for monitoring and managing water quality on a large scale and in a timely and cost-efficient manner, each SRI focuses on only two or three sensitive waveband combinations. This makes it difficult to build effective SRIs to estimate water quality under different potentially confounding factors, such as the large variation in the concentrations and types of water components, as well as their influence from the saturation level of the investigated water quality parameters. In addition, the limited number of wavebands increases the sensitivity of many wavebands involved in the SRIs for different water components rather than the target parameters. For instance, Wang et al. [63] found that it is difficult to detect TSS using a single waveband or two waveband combinations in relatively clear water. However, the combination of three wavebands was successful to estimate Chl-a contents in turbid water bodies $[69,70]$. Therefore, recent studies have considered different PLSR models that are based on full-spectrum wavelengths or multiple SRIs for improving the estimation of different IWQIs [19,20,63,71]. For instance, Wang et al. [63] reported that PLSR models based on several selected wavebands exhibited better predictive abilities of inland water quality parameters than models that use single wavebands or two waveband combinations. The PLSR models based on waveband selection from the range from 400 to $900 \mathrm{~nm}$ substantially improved prediction for both chlorophyll-a and TSS, for which the $\mathrm{R}^{2}$ increased from 0.43 and 0.40 for single waveband or two waveband combinations to 0.98 and 0.97 for PLSR models, respectively. Xing et al. [19] also reported that incorporating the most sensitive wavebands, which were chosen via variable importance in projection, in the PLSR model increased the efficiency of the estimation of several wastewater quality parameters, such as COD, 
BOD, TDS, TH, TA, and $\mathrm{NH}_{3}-\mathrm{N}$. In this study, the performance of PLSR models that were based on the full-spectrum ranges of 302-1148 nm (Table 7) or all fourteen SRIs (Figure 8) were tested for their estimation of different IWQIs. The results showed that the PLSR models based on all SRIs provided a more accurate estimation of different IWQIs for both the Cal. and Val. datasets $\left(R^{2}\right.$ ranged from 0.66 to 0.82 in the Cal. and from 0.54 to 0.77 in the Val.; Figure 8) than those PLSR models based on the full-spectrum ranges of $302-1148 \mathrm{~nm}\left(R^{2}\right.$ ranged from 0.39 to 0.79 in the Cal. and from 0.32 to 0.60 in the Val.; Table 7). In addition, both PLSR models were better than the individual SRIs for estimating IWQIs. The PLSR models based on SRIs also provided a good relationship between calculated and predicted values for all parameters of IWQIs (Figure 8). Once again, these findings confirm that PLSR models based on various SRIs or the full-spectrum range can provide additional improvements to the estimation of different groundwater quality parameters and can be considered as a unified approach for remote quantification of constituent concentrations in water quality assessment. This is because the different models of PLSR include several sensitive wavebands that cover all the main variations in the water components and are directly related to the main changes in the targeted water quality parameters.

\section{Conclusions}

In this study, the groundwater quality of the El Fayoum depression in the Western Desert and the Central Nile Delta was assessed traditionally using different physiochemical parameters, IWQIs, and hydrochemical facies in conjunction with non-destructive high-throughput passive sensing as a rapid and cost-effective assessment tool. Spectral reflectance water surface data were used to develop different SRIs, and the performance of these SRIs and different PLSR models based on SRIs or the full-spectrum range were compared for their assessment of IWQIs. The results of the study provided several conclusions. The groundwater of the WD showed more substantial variation in physiochemical parameters and IWQIs than the CND. According to the IWQ, \%Na, SAR, SSP, PS, and KI, approximately $6.7 \%, 26.7 \%, 60.0 \%, 46.7 \%, 6.7 \%$, and $53.3 \%$ of groundwater samples in the WD are suitable for irrigation purposes and classified low restriction, good, excellent, good, excellent to good, and suitable, respectively, indicating that this water type is only suitable for well-drained soils. However, almost all $(85-100 \%)$ groundwater samples of the CND are very suitable for irrigation. Based on hydrochemical facies, the major groundwater of the $\mathrm{WD}$ and $\mathrm{CND}$ were $\mathrm{Na}-\mathrm{Cl}$ and $\mathrm{Ca}-\mathrm{HCO}_{3}$, respectively, based on Piper's diagram. Based on Chadha's plot, most of the samples of the WD and CND found in field 2 (alkali metals $\left(\mathrm{Na}^{+}+\mathrm{K}^{+}\right)$exceed alkaline earth metals $\left(\mathrm{Ca}^{2+}+\mathrm{Mg}^{2+}\right)$ and field 1 (alkaline earth metals $\left(\mathrm{Ca}^{2+}+\mathrm{Mg}^{2+}\right)$ exceed alkali metals $\left(\mathrm{Na}^{+}+\mathrm{K}^{+}\right)$, respectively. The most developed and published SRIs, which were developed as a ratio between combination of UV/VIS, UV/NIR, VIS/VIS, VIS/NIR, and NIR/NIR, exhibited moderate, weak, and moderate to strong correlations with IWQIs and several physiochemical parameters in the WD, CND, and across both regions, respectively. The PLSR models based on all SRIs provided a more accurate estimation of different IWQIs in both the Cal. and Val. datasets than those PLSR models that were based on the full-spectrum ranges (302-1148 nm), and both PLSR models were better than the individual SRIs at estimating IWQIs. In addition, the PLSR models that were based on SRIs provided a good relationship between calculated and predicted values for all parameters of IWQIs. The results of this study, which has rarely been conducted in irrigated arid and semiarid regions, provide useful insights for future analyses on the assessment and management of groundwater quality in these regions, especially when using a high-throughput remote sensing tool.

Author Contributions: Conceptualization, M.G., S.E. and S.E.-H.; methodology, M.G., S.E. and S.E.-H.; software, N.A.-S., M.U.T. and M.M.; validation, S.E.-H., S.E., M.G. and N.A.-S.; formal analysis, S.E.-H., S.E., M.G., M.U.T. and M.M.; investigation, S.E.-H., S.E. and M.G.; resources, S.E.-H., S.E., M.G. and N.A.-S.; data curation, M.M. and N.A.-S.; writing — original draft preparation, S.E.-H., S.E. and M.G.; writing — review and editing, S.E.-H.; visualization, S.E., S.E.-H. and M.G.; supervision, S.E.-H. and S.E.; project administration, M.G., S.E. and S.E.-H.; funding acquisition, S.E.-H., S.E., N.A.-S. and M.A. All authors have read and agreed to the published version of the manuscript. 
Funding: This research was funded by Deanship of Scientific Research at the King Saud University, Saudi Arabia, grant number RG-1435-032.

Acknowledgments: The authors extend their appreciation to the Deanship of Scientific Research at the King Saud University, Saudi Arabia for funding this work through Research Group no. (RG-1435-032), and the Researchers Support and Services Unit (RSSU) for their technical support.

Conflicts of Interest: The authors declare no conflict of interest.

\section{References}

1. Perry, C.; Steduto, P.; Allen, R.G.; Burt, C.M. Increasing productivity in irrigated agriculture: Agronomic constraints and hydrological realities. Agric. Water Manag. 2009, 96, 1517-1524. [CrossRef]

2. Zektser, I.S.; Everett, L.G. Groundwater Resources of the World and Their Use; IHP-VI Series on Groundwater No 6; UNESCO: Paris, France, 2004.

3. Brown, R.M.; McClelland, N.I.; Deininger, R.A.; Tozer, R.G.; Water, A. Quality index: Do we dare? Water Sewage Works 1970, 117, 339-343.

4. Singh, S.K.; Srivastava, P.K.; Singh, D.; Han, D.; Gautam, S.K.; Pandey, A.C. Modeling groundwater quality over a humid subtropical region using numerical indices, earth observation datasets, and X-ray diffraction technique: A case study of Allahabad district, India. Environ. Geochem. Health 2015, 37, 157-180. [CrossRef] [PubMed]

5. Gautam, S.K.; Maharana, C.; Sharma, D.; Singh, A.K.; Tripathi, J.K.; Singh, S.K. Evaluation of groundwater quality in the Chotanagpur Plateau region of the Subarnarekha River Basin, Jharkhand State, India. Sustain. Water Qual. Ecol. 2015, 6, 57-74. [CrossRef]

6. Meireles, A.C.M.; Andrade, E.M.; Chaves, L.C.G.; Frischkorn, H.; Crisóstomo, L.A. A new proposal of the classification of irrigation water. Rev. Cienc. Agron. 2010, 41, 349-357. [CrossRef]

7. Rawat, K.S.; Singh, S.K.; Gautam, S.K. Assessment of groundwater quality for irrigation use: A peninsular case study. Appl. Water Sci. 2018, 8, 233. [CrossRef]

8. Khalid, S. An assessment of groundwater quality for irrigation and drinking purposes around brick kilns in three districts of Balochistan Province, Pakistan, through water quality index and multivariate statistical approaches. J. Geochem. Explor. 2019, 197, 14-26.

9. Saeedi, M.; Abessi, O.; Sharifi, F.; Meraji, H. Development of groundwater quality index. Environ. Monit. Assess. 2010, 163, 327-335. [CrossRef]

10. Lai, Y.C.; Chien, C.C.; Yang, Z.H.; Surampalli, R.Y.; Kao, C.M. Developing an integrated modeling tool for river water quality index assessment. Water Environ. Res. 2017, 89, 260-273. [CrossRef]

11. Şener, Ş.; Şener, E.; Davraz, A. Evaluation of water quality using water quality index (WQI) method and GIS in Aksu River (Sw-turkey). Sci. Total Environ. 2017, 584, 131-144. [CrossRef]

12. Wang, X.; Zhang, F.; Ding, J. Evaluation of water quality based on a machine learning algorithm and water quality index for the Ebinur Lake Watershed, China. Sci. Rep. 2017, 7, 12858. [CrossRef] [PubMed]

13. Abd-Elrahman, A.; Croxton, M.; Pande-Chettri, R.; Toor, G.S.; Smith, S.; Hill, J. In situ estimation of water quality parameters in freshwater aquaculture ponds using hyperspectral imaging system. ISPRS J. Photogramm. Remote Sens. 2011, 66, 463-472. [CrossRef]

14. Logeshkumaran, A.; Magesh, N.S.; Godson, P.S.; Chandrasekar, N. Hydro-geochemistry and application of water quality index (DWQI) for groundwater quality assessment, Anna Nagar, part of Chennai City, Tamil Nadu, India. Appl. Water Sci. 2015, 5, 335-343. [CrossRef]

15. Gitelson, A.; Garbuzov, G.; Szilagyi, F.; Mittenzwey, K.H.; Karnieli, A.; Kaiser, A. Quantitative remote-sensing methods for real-time monitoring of inland waters quality. Int. J. Remote Sens. 1993, 14, 1269-1295. [CrossRef]

16. Santini, F.; Alberotanza, L.; Cavalli, R.M.; Pignatti, S. A two-step optimization procedure for assessing water constituent concentrations by hyperspectral remote sensing techniques: An Application to the Highly Turbid Venice Lagoon Waters. Remote Sens. Environ. 2010, 114, 887-898. [CrossRef]

17. Brando, V.E.; Braga, F.; Zaggia, L.; Giardino, C.; Bresciani, M.; Matta, E.; Bellafiore, D.; Ferrarin, C.; Maicu, F.; Benetazzo, A.; et al. High-resolution satellite turbidity and sea surface temperature observations of river plume interactions during a significant flood event. Ocean Sci. 2015, 11, 909-920. [CrossRef]

18. Gholizadeh, M.H.; Melesse, A.M.; Reddi, L.A. A Comprehensive review on water quality parameters estimation using remote sensing techniques. Sensors 2016, 16, 1298. [CrossRef] 
19. Xing, Z.; Chen, J.; Zhao, X.; Li, Y.; Li, X.; Zhang, Z.; Lao, C.; Wang, H. Quantitative estimation of wastewater quality parameters by hyperspectral band screening using GC, VIP and SPA. PeerJ 2019, 7, e8255. [CrossRef]

20. Song, K.; Li, L.; Li, S.; Tedesco, L.; Hall, B.; Li, L. Hyperspectral remote sensing of total phosphorus (TP) in three central Indiana water supply reservoirs. Water Air Soil Pollut. 2012, 223, 1481-1502. [CrossRef]

21. Giardino, C.; Bresciani, M.; Cazzaniga, I.; Schenk, K.; Rieger, P.; Braga, F.; Matta, E.; Brando, V.E. Evaluation of multi-resolution satellite sensors for assessing water quality and bottom depth of Lake Garda. Sensors 2014, 14, 24116-24131. [CrossRef]

22. Vinciková, H.; Hanuš, J.; Pechar, L. Spectral reflectance is a reliable water-quality estimator for small, highly turbid wetlands. Wetlands Ecol. Manag. 2015, 23, 933-946. [CrossRef]

23. Shareef, M.A.; Khenchaf, A.; Toumi, A. Integration of passive and active microwave remote sensing to estimate water quality parameters. In Proceedings of the IEEE Radar Conference (RadarConf), Philadelphia, PA, USA, 2-6 May 2016; pp. 1-4.

24. Xiao, R.; Wang, G.; Zhang, Q.; Zhang, Z. Multi-scale analysis of relationship between landscape pattern and urban river water quality in different seasons. Sci. Rep. 2016, 6, 25250. [CrossRef] [PubMed]

25. Yang, Y.; Gao, B.; Hao, H.; Zhou, H.; Lu, J. Nitrogen and phosphorus in sediments in china: A national-scale assessment and review. Sci. Total Environ. 2017, 576, 840-849. [CrossRef]

26. Elhag, M.; Gitas, I.; Othman, A.; Bahrawi, J.; Gikas, P. Assessment of water quality parameters using temporal remote sensing spectral reflectance in arid environments, Saudi Arabia. Water 2019, 11, 556. [CrossRef]

27. Wei, L.; Huang, C.; Zhong, Y.; Wang, Z.; Hu, X.; Lin, L. Inland waters suspended solids concentration retrieval based on PSO-LSSVM for UAV-borne hyperspectral remote sensing imagery. Remote Sens. 2019, 11, 1455. [CrossRef]

28. Kipp, S.; Mistele, B.; Schmidhalter, U. The performance of active spectral reflectance sensors as influenced by measuring distance, device temperature and light intensity. Comput. Electron. Agric. 2014, 100, 24-33. [CrossRef]

29. Miller, R.L.; DelCastillo, C.E.; Powell, R.T.; DSa, E.; Spiering, B. Mapping CDOM Concentration in Waters Influenced by the Mississippi River Plume; NASA Technical Reports Server: Cleveland, OH, USA, 2002.

30. Shafique, N.A.; Fulk, F.; Autrey, B.C.; Flotemersch, J. Hyperspectral remote sensing of water quality parameters for large rivers in the Ohio River Basin. In Proceedings of the First Interagency Conference on Research in the Watersheds, Benson, AZ, USA, 27-30 October 2003.

31. Osinska-Skotak, K.; Kruk, M.; Mróz, M. The Spatial Diversification of Lake Water Quality Parameters in Mazurian Lakes in Summertime; Millpress: Rotterdam, The Netherlands, 2007.

32. Wu, C.F.; Wu, J.P.; Qi, J.G.; Zhang, L.S.; Huang, H.Q.; Lou, L.P.; Chen, Y. Empirical estimation of total phosphorus concentration in the mainstream of the Qiantang River in China using Landsat TM data. Inter. J. Remote Sens. 2010, 31, 2309-2324. [CrossRef]

33. Elsayed, S.; Elhoweity, M.; Ibrahim, H.H.; Dewir, Y.H.; Migdadi, H.M.; Schmidhalter, U. Thermal imaging and passive reflectance sensing to estimate the water status and grain yield of wheat under different irrigation regimes. Agric. Water Manag. 2017, 189, 98-110. [CrossRef]

34. Garriga, M.; Romero-Bravo, S.; Estrada, F.; Escobar, A.; Matus, I.A.; del Pozo, A.; Astudillo, C.A.; Lobos, G.A. Assessing wheat traits by spectral reflectance: Do we really need to focus on predicted trait-values or directly identify the elite genotypes group? Front. Plant Sci. 2017, 8, 280. [CrossRef]

35. APHA (American Public Health Association). Standard Methods for the Examination of Water and Wastewater, 17th ed.; American Public Health Association: Washington, DC, USA, 2012.

36. Todd, D.K. Groundwater Hydrology, 1st ed.; John Wiley and Sons, Inc.: Hoboken, NJ, USA, 1960; p. 336.

37. Richards, L.A. Diagnosis and Improvement of Saline and Alkali Soils; Soil Science; United States Department of Agriculture: Washington, DC, USA, 1954; p. 78.

38. Doneen, L.D. Notes on Water Quality in Agriculture; Published as a Water Science and Engineering, Paper 4001; Department of Water Science and Engineering, University of California: Oakland, CA, USA, 1964.

39. Kelly, W.P. Permissible composition and concentration of irrigated waters. Proc. Am. Soc. Civ. Eng. 1940, 66, 607-613.

40. Kachroud, M.; Trolard, F.; Kefi, M.; Jebari, S.; Bourrié, G. Water quality indices: Challenges and application limits in the literature. Water 2019, 11,361. [CrossRef]

41. Piper, A.M. A graphic procedure in the geochemical interpretation of water-analyses. Trans. AGU 1944, 25, 914-928. [CrossRef] 
42. Chadha, D.K. A proposed new diagram for geochemical classification of natural waters and interpretation of chemical data. Hydrogeol. J. 1999, 7, 431-439. [CrossRef]

43. Peńuelas, J.; Pinol, J.; Ogaya, R.; Filella, I. Estimation of plant water concentration by the reflectance water Index WI (R900/R970). Int. J. Remote Sens. 1997, 18, 2869-2875. [CrossRef]

44. Prasad, B.; Carver, B.F.; Stone, M.L.; Babar, M.A.; Raun, W.R.; Klatt, A.R. Genetic analysis of indirect selection for winter wheat grain yield using spectral reflectance indices. Crop Sci. 2007, 47, 1416-1425. [CrossRef]

45. Wold, S.; Sjöström, M.; Eriksson, L. PLS-regression: A basic tool of chemometrics. Chemom. Intell. Lab. Syst. 2001, 58, 109-130. [CrossRef]

46. Chen, S.; Hong, X.; Harris, C.J.; Sharkey, P.M. Sparse modeling using orthogonal forward regression with PRESS statistic and regularization. IEEE Trans. Syst. Man Cybern. B Cybern. 2004, 34, 898-911. [CrossRef]

47. Boyacioglu, H. Surface water quality assessment using factor analysis. Water SA 2006, 32, 389-393. [CrossRef]

48. Rocha, F.C.; Andrade, E.M.; Lopes, F.B. Water quality index calculated from biological, physical and chemical attributes. Environ. Monit. Assess. 2015, 187, 4163. [CrossRef]

49. Suarez, D.L.; Wood, J.D.; Lesch, S.M. Effect of SAR on water infiltration under a sequential rain-irrigation management system. Agric. Water Manag. 2006, 86, 150-164. [CrossRef]

50. Sharma, D.A.; Rishi, M.S.; Keesari, T. Evaluation of groundwater quality and suitability for irrigation and drinking purposes in southwest Punjab, India using hydrochemical approach. Appl. Water Sci. 2017, 7, 3137-3150. [CrossRef]

51. Tahmasebi, P.; Mahmudy-Gharaie, M.H.; Ghassemzadeh, F.; Karimi Karouyeh, A.K. Assessment of groundwater suitability for irrigation in a gold mine surrounding area, NE Iran. Environ. Earth Sci. 2018, 77, 766. [CrossRef]

52. Chen, J.; Huang, Q.; Lin, Y.; Fang, Y.; Qian, H.; Liu, R.; Ma, H. Hydrogeochemical characteristics and quality assessment of groundwater in an irrigated region, Northwest China. Water 2019, 11, 96. [CrossRef]

53. Oyiga, B.C.; Sharma, R.C.; Shen, J.; Baum, M.; Ogbonnaya, F.C.; Léon, J.; Ballvora, A. Identification and characterization of salt tolerance of wheat germplasm using a multivariable screening approach. $J$. Agron. Crop Sci. 2016, 202, 472-485. [CrossRef]

54. El-Hendawy, S.E.; Hassan, W.M.; Al-Suhaibani, N.A.; Refay, Y.; Abdella, K.A. Comparative performance of multivariable agro-physiological parameters for detecting salt tolerance of wheat cultivars under simulated saline field growing conditions. Front. Plant Sci. 2017, 8, 435. [CrossRef]

55. El Sheikh, A.E. Water Budget Analysis of the Quaternary Deposits for the Assessment of the Water Logging Problem of El Fayoum Depression. Ph.D. Thesis, Faculty of Science, Al-Azhr University, Cairo, Egypt, 2004; p. 233.

56. Gad, M.; El-Hattab, M. Integration of water pollution indices and DRASTIC model for assessment of groundwater quality in El Fayoum Depression, western desert, Egypt. J. Afr. Earth Sci. 2019, 158, 103554. [CrossRef]

57. Ahmed, M.A. Assessment of intrinsic vulnerability to contamination for the Alluvial aquifer in El-Fayoum Depression using the DRASTIC method. J. Radiat. Res. Appl. Sci. 2012, 5, 743-768.

58. Negm, A.M.; Sakr, S.; Abd-Elaty, I.; Abd-Elhamid, H.F. An overview of groundwater resources in Nile Delta aquifer. In Groundwater in the Nile Delta; Springer: Cham, Switzerland, 2018; pp. 3-44.

59. Varol, S.; Davraz, A. Assessment of geochemistry and hydrogeochemical processes in groundwater of the Tefenni plain (Burdur/Turkey). Environ. Earth Sci. 2014, 71, 4657-4673. [CrossRef]

60. Prasanna, M.V.; Chidambaram, S.; Shahul Hameed, A.; Srinivasamoorthy, K. Study of evaluation of groundwater in Gadilam basin using hydrogeochemical and isotope data. Environ. Monit. Assess. 2010, 168, 63-90. [CrossRef]

61. Duan, W.; He, B.; Takara, K.; Luo, P.; Nover, D.; Sahu, N.; Yamashiki, Y. Spatiotemporal evaluation of water quality incidents in Japan between 1996 and 2007. Chemosphere 2013, 93, 946-953. [CrossRef]

62. Deng, Y.; Zhang, Y.; Li, D.; Shi, K.; Zhang, Y. Temporal and spatial dynamics of phytoplankton primary production in Lake Taihu derived from MODIS data. Remote Sens. 2017, 9, 195. [CrossRef]

63. Wang, Z.; Kawamura, K.; Sakuno, Y.; Fan, X.; Gong, Z.; Lim, J. Retrieval of chlorophyll-a and total suspended solids using iterative stepwise elimination partial least squares (ISE-PLS) regression based on field hyperspectral measurements in irrigation ponds in Higashihiroshima, Japan. Remote Sens. 2017, 9, 264. [CrossRef] 
64. Zhang, Y.; Giardino, C.; Li, L. Water optics and water colour remote sensing. Remote Sens. 2017, 9, 818. [CrossRef]

65. Seyhan, E.; Dekker, A. Application of remote sensing techniques for water quality monitoring. Hydrol. Biol. Bull. 1986, 20, 41-50. [CrossRef]

66. El-Din, M.S.; Gaber, A.; Koch, M.; Ahmed, R.S.; Bahgat, I. Remote sensing application for water quality assessment in lake timsah, Suez Canal, Egypt. J. Remote Sens. Technol. 2013, 1, 61-74. [CrossRef]

67. Wu, J.L.; Ho, C.R.; Huang, C.C.; Srivastav, A.L.; Tzeng, J.H.; Lin, Y.T. Hyperspectral sensing for turbid water quality monitoring in freshwater rivers: Empirical relationship between reflectance and turbidity and total solids. Sensors 2014, 14, 22670-22688. [CrossRef] [PubMed]

68. Lerch, R.N.; Baffaut, C.; Kitchen, N.R.; Sadler, E.J. Long-term agroecosystem research in the Central Mississippi River Basin: Dissolved nitrogen and phosphorus transport in a high-runoff-potential watershed. J. Environ. Qual. 2015, 44, 44-57. [CrossRef]

69. Gitelson, A.A.; Schalles, J.F.; Hladik, C.M. Remote chlorophyll-a retrieval in turbid, productive estuaries: Chesapeake Bay case study. Remote Sens. Environ. 2007, 109, 464-472. [CrossRef]

70. Gitelson, A.A.; Dall'Olmo, G.; Moses, W.; Rundquist, D.C.; Barrow, T.; Fisher, T.R.; Gurlin, D.; Holz, J. A simple semi-analytical model for remote estimation of chlorophyll-a in turbid waters: Validation. Remote Sens. Environ. 2008, 112, 3582-3593. [CrossRef]

71. Ryan, K.; Ali, K. Application of a partial least-squares regression model to retrieve chlorophyll-a concentrations in coastal waters using hyper-spectral data. Ocean Sci. J. 2016, 51, 209-221. [CrossRef]

(C) 2020 by the authors. Licensee MDPI, Basel, Switzerland. This article is an open access article distributed under the terms and conditions of the Creative Commons Attribution (CC BY) license (http://creativecommons.org/licenses/by/4.0/). 